\title{
OS SETE PILARES DA TÉCNICA PIANÍSTICA ${ }^{1}$
}

SEVEN PILLARS OF THE PIANO TECHNIQUE

Laura Boaventura Melo ${ }^{2}$ Universidade Federal de Minhas Gerais (UFMG)

laurabva@hotmail.com

Cristina Capparelli Gerling

Universidade Federal do Rio Grande do Sul (UFRGS) cgerling@ufrgs.br 


\section{Resumo}

A técnica pianística tem sido amplamente discutida, entretanto, ainda é comum nos depararmos com crenças de que a mesma depende de fatores como o talento nato, o esforço repetitivo ou o tamanho das mãos. A perpetuação desse pensamento pode culminar em dores, lesões, problemas emocionais e até mesmo na interrupção definitiva das atividades artísticas. $O$ presente artigo tem como objetivo analisar e sistematizar abordagens que promovem uma maneira saudável, racional e musical de se pensar a técnica pianística por meio de sete categorias ou pilares: postura corporal, coordenação dos movimentos, função do braço, movimentos semicirculares inferiores e superiores, movimentos rotatórios, deslocamento lateral progressivo no teclado e agrupamentos de leitura e realização. Conclui-se que, apesar da constatação de pequenas discordâncias entre os autores, há uma convergência na busca pela eficácia pianística por meio do bem-estar físico, traduzido no desenvolvimento da consciência corporal e, consequentemente, na qualidade e variedade sonora. A categorização dos pilares promove o acesso mais claro aos conceitos analisados e permite uma maior eficiência na sua aplicação.

Palavras-chave: técnica pianística, categorias de movimento saudável, consciência corporal.

\section{Abstract}

Piano technique has been widely discussed, and yet we are frequently confronted with outmoded beliefs concerning its dependence on factors such as natural talent, repetitive effort or hand size. The perpetuation of these antiquated notions can culminate in pain, injury, emotional problems, and even the definitive interruption of any artistic activity. This article aims to analyze and systematize approaches that strive for a healthy, rational and musical ways of thinking piano technique and categorize them into seven pillars: body posture, movement coordination, arm functions, including semi-circular and rotational movements, lateral displacement on the keyboard and note grouping for enhanced cognition and technical mastery. It is concluded that, despite of small disagreements between the authors, there is a convergence in the search of pianistic efficacy through physical well-being, translated into the development of body awareness and, consequently, in the quality and variety of sound. The categorization of the pillars, in turn, promotes easier access to the analyzed concepts and allows greater efficiency in their application.

Keywords: Piano technique. Categories of healthy and efficient movements. Corporal conscience.

\footnotetext{
1 Uma versão muito resumida deste texto foi apresentada no congresso da Abrapem em 2019.

2 Laura Boaventura, professora adjunta de piano da UFMG, graduou-se na classe da Professora Dra Celina Szrvinsk (UFMG), obteve o título mestre pelo Conservatório Rimsky Korsakov de São Petersburgo (Rússia) na classe de piano solo de Nadezha Esmond, música de câmara de Yulia Fedoseeva e acompanhamento de cantores de Irina Sharapova e de doutora em Música - Práticas interpretativas pela UFRGS sob a orientação da Professora Dra Cristina Capparelli. Sua pesquisa de doutorado investigou abordagens saudáveis, musicais e eficientes da técnica pianística. 3 Cristina Capparelli Gerling distingue-se por conciliar as atividades de pianista, pedagoga e pesquisadora. Professora na Universidade Federal do Rio Grande do Sul desde 1985, foi a primeira coordenadora do Programa de Pós-Graduação em Música iniciado em 1987, tendo se tornado professora titular em 1996. Com vários CDs de música brasileira e latino-americana gravados, e com uma expressiva carreira artística, seus trabalhos investigativos voltam-se para a prática efetiva do instrumento, a projeção da expressividade na execução ao piano, bem como tópicos pontuais sobre a ansiedade do músico, memorização e bem-estar na execução musical. Além de premiados em concursos de instrumento, seus orientandos têm sido igualmente selecionados como docentes em escolas de renome no país e no exterior. Os resultados de suas pesquisas têm sido divulgados em revistas especializadas tais como Frontiers in Pschology - Performance Science da qual é editora convidada.
} 


\section{INTRODUÇÃO}

A técnica pianística tem sido o foco de estudo de numerosos pedagogos e pianistas em uma considerável amplitude de tempo, idiomas, abordagens e opiniões. Entretanto, apesar dos esforços voltados para a sua discussão e compreensão, muitos educadores têm ensinado por meio da reprodução de ideias que mistificam o seu aprendizado. A precariedade no conhecimento necessário para a resolução de problemas de natureza mecânica, tanto pela falta de acesso quanto pela dificuldade de entendimento das demandas interpretativas, impede a realização musical e prejudica a plena satisfação artística do pianista. Não obstante a crescente preocupação com a busca do bem-estar físico na execução, encontramos ainda um grande número de estudantes e profissionais que se queixam de dores ou incômodos ao executar certas passagens musicais consideradas tecnicamente difíceis. Essa simples constatação, muitas vezes, não ultrapassa o limite das indagações e não possibilita o encontro de resultados efetivos para a solução de problemas, que podem levar a frustrações, traumas físicos e desinteresse musical.

A sistematização dos principais conceitos da técnica pianística e as categorias propostas a seguir visam assistir o profissional do piano na decodificação da abordagem sugerida e auxiliá-lo quanto à sua aplicação. A relevância de um elenco de sugestões aqui apresentadas e que foram previamente testadas em situações reais reside no fato de que a literatura sobre técnica pianística é tão vasta quanto cheia de opiniões contraditórias. Entretanto, a solução para um problema surgido no estudo ou mesmo na aula de piano requer um diagnóstico rápido e eficiente. Essa possível chave pode ser mais facilmente acessada em um contexto de organização e síntese.

\section{PILARES DA TÉCNICA PIANÍSTICA}

Com base na obra dos principais pensadores da técnica pianística, dentre os quais Matthay $4(1903,1932,1939,1947)$ e Ortmann ${ }^{5}$ (1929), e especialmente no trabalho de seus seguidores, como, por exemplo, Dorothy Taubman, ${ }^{6}$ para a obtenção de um entendimento da técnica pianística, organizamos conceitos fundamentais em sete pilares: postura corporal, coordenação dos movimentos, função do braço, movimentos semicirculares inferiores e superiores, movimentos rotatórios, deslocamento lateral

\footnotetext{
4 Tobias Matthay (1858-1945) foi um influente pedagogo inglês. Apesar de ser frequentemente associado à escola do relaxamento, propôs conceitos mais complexos e direcionados a evitar a perda de energia entre o pianista e o teclado. 0 autor defende o uso do peso do braço, porém associado à coordenação com a atividade digital. Advoga também pela distensão, desde que associada ao movimento de níveis apropriados de contração do músculo opositor. Seus estudos sobre a rotação, classificada como visível e invisível, influenciaram pedagogos como Dorothy Taubman, Seymour Fink (1991) e Seymour Bernstein (1981).

5 Otto Ortmann (1889-1979) destaca-se pela introdução do pensamento científico na realização pianística. Seus experimentos, realizados em laboratório, estabeleceram relações entre os mecanismos da física, anatomia humana e técnica pianística. Apesar desse esforço, seu trabalho recebeu críticas pela dificuldade de aplicação prática.

6 Dorothy Taubman (1917-2013), notável pedagoga americana, se destacou pela contribuição para a construção de uma abordagem pianística que prezasse pelo virtuosismo saudável, no qual movimentos coordenados promovem o menor esforço com o melhor resultado. Taubman não publicou livros ou métodos durante sua jornada pedagógica. Seu legado tornou-se conhecido em virtude do empenho de seus discípulos em publicar estudos científicos e realizar seminários, master classes, cursos e palestras em várias partes do mundo.
} 
progressivo no teclado e agrupamentos de leitura e realização. Torna-se importante salientar que esses pilares, nomeados a partir de situações pianísticas reais, são flexíveis e interdependentes. Em cada trecho musical apresentado as categorias se entrecruzam, assim, a execução efetiva depende tanto do entendimento das demandas em cada passagem quanto da coordenação de soluções. O corpo do pianista, incluindo seu cérebro, funciona melhor em coordenação do que no isolamento de atividades. Não há, portanto, hierarquia entre os pilares, visto que cada problema apresentado dificilmente será sanado com a resolução apenas de um aspecto específico. Assim, os sete pilares agregam elementos motores, mas também musicais e cognitivos. Entretanto, com o objetivo de melhor fixar o conceito, cada pilar será particularmente discutido.

\subsection{POSTURA CORPORAL}

A postura tem sido, desde os primeiros tratados sobre a técnica dos instrumentos de teclado, um assunto amplamente discutido. Dentre os escritores mais recentes, Seymour Fink destaca sua importância logo nas primeiras páginas de seu trabalho: "Eu acredito que o foco central do estudo técnico seja a mecânica do movimento do corpo do pianista: a forma como se posiciona, a forma como funciona, as sensações que experimenta e o movimento que produz" (FINK, 1992, p.13, tradução nossa). ${ }^{7}$ Segundo Torres (2017, p.257), para Erwin Johannes Bach, ${ }^{8}$ a postura corporal exerce um papel fundamental na performance pianística. De acordo com o pedagogo alemão, se a postura corporal não está correta, a respiração torna-se mais difícil, o que ocasiona um aumento do ritmo cardíaco, agravando-se consequentemente o nervosismo. Defende também que uma respiração correta traz efeitos positivos para o fluxo da corrente sanguínea, o que evita que as mãos fiquem frias. Já para Matthay, a postura tinha um papel secundário, dependente das condições musculares: "Se as condições musculares estiverem corretas, a posição do corpo cuidará de si mesma" (MATTHAY, 1947, p.105, tradução nossa). ${ }^{9}$ Sandor (1981, p.34) concorda com esse raciocínio ao dizer que a postura está correta quando se tem a sensação de conforto e de um corpo bem balanceado, com o diafragma e outros músculos em equilíbrio para que a respiração ocorra sem qualquer impedimento.

Vários pedagogos recomendam que os antebraços, ao se alinharem com o teclado, se posicionem em paralelo ao chão. Surgem, no entanto, divergências que podem ser observadas entre Fielden (1949) e Sandor (1981). O primeiro concorda com essa prática recomendada por Matthay (1903, p.302). Para Fielden (1949, p.51), essa é a melhor posição, pois facilita a sensação do ponto de contato e libera o pulso para executar

\footnotetext{
7 Original: "I believe that the central focus of technical study is the movement mechanics of the player's body: the way it is positioned, the way it functions, the sensations it feels, and the movement it produces" (FINK, 1992, p.13).

8 Erwin Johannes Bach nasceu em 13 de outubro de 1897 em Hildesheim, Alemanha. Além de piano, composição, regência, história da música e ornamentação, cursou o primeiro ano de medicina, o que lhe forneceu base científica para o desenvolvimento de seu tratado de técnica pianística Die Vollendete Klaviertechnik. Seu trabalho, publicado em 1929, foi traduzido em uma versão resumida para o inglês, sérvio e russo. 0 pedagogo alemão faleceu em 19 de agosto de 1961 em Berlim em decorrência de uma tentativa de suicídio provocada após sofrer um derrame cerebral e perder suas habilidades pianísticas.
}

9 Original: "If the muscular conditions are right, the position of the body will take care of itself" (MATTHAY, 1947, p.105). 
movimentos verticais. Entretanto, Sandor (1981, p.31) sustenta a opinião de que esse alinhamento não deve ser fixo, mas deve variar de acordo com o tamanho da parte superior do braço. Dessa forma, se ela for muito curta, é recomendável que o antebraço forme um pequeno ângulo com o teclado. Se for longa, deve-se optar, então, por uma posição mais baixa.

Outro ponto importante diz respeito ao papel do tronco na técnica pianística. Fink (1992, p.13) defende que seu correto alinhamento propicia o uso econômico e balanceado dos músculos. T. E. Milanovic (2011c, p.103), em sua tese sobre a abordagem Taubman, atenta para o aspecto da mobilidade. Segundo ela, a posição do tronco se ajusta ligeiramente para trás quando as mãos estão posicionadas em frente do corpo e para frente quando as mãos se aproximam dos extremos, agudo e grave. Esses extremos do teclado já representavam uma fonte de preocupação para Matthay $(1947$, p.105), que aconselhava assentar-se a uma distância na qual o cotovelo pudesse se mover na frente do corpo e não impedisse que se atingissem com facilidade os pontos mais distantes no teclado. Tanto Taubman quanto Matthay (1947, p.105) concordam que se sentar muito perto do teclado traz prejuízos para o desenvolvimento de uma técnica saudável. Já para Schultz (1936, p.39), a inclinação do tronco para trás não é aconselhada. Segundo o autor, o peso da unidade que toca não deve nunca permanecer completamente sobre as teclas. Alguma quantidade de peso deve ser necessariamente suportada pela articulação em que essa unidade oscila. Entretanto, cada vez que o tronco se posiciona para trás, mais peso aloja-se nas teclas, visto que a parte mais pesada da unidade, o braço, aproxima-se do plano horizontal. Em outras palavras, Schultz afirma que a posição normal do braço ao instrumento exige que a sua parte superior seja levantada para frente, abduzida levemente para o lado do corpo e girada em direção ao teclado. $O$ antebraço é levado a um plano horizontal no nível das teclas, com a mão apoiada para evitar que seu peso as pressione. Segundo Schultz, o centro de gravidade do braço, ou o ponto de equilíbrio, está localizado na articulação logo abaixo do cotovelo, e o peso da unidade não repousa completamente sobre as teclas. Ou seja, o cuidado com a postura e o reconhecimento da importância do tronco superior estabilizado, ainda que flexível, também contribui ativamente para o manejo e a coordenação dos braços, antebraços, mãos e dedos. Como essa unidade se aproxima de uma linha horizontal, uma carga menor do peso é distribuída entre as articulações, e a energia se direciona mais diretamente para o teclado. Assim, cada vez mais energia é direcionada para as teclas à medida que o tronco é inclinado para trás do teclado. Portanto, inclinar-se para trás deve ser evitado para que o peso possa ser trazido para as teclas na medida certa deliberada pelo pianista.

Segundo as considerações de Milanovic (2011c, p.103) em Learning and Teaching Healthy Piano Technique: Training as an Instructor in the Taubman Approach, e seguindo rigorosamente a abordagem proposta por Taubman, a manutenção de uma postura adequada depende do apoio paralelo dos pés no chão. Apesar de ter se declarado fortemente influenciada por Matthay, notamos que, nesse aspecto, as concepções dos autores se diferem. Matthay (1903, p.305), apesar de concordar que os pés devem descansar no chão, sugere que o pé esquerdo fique ligeiramente para trás para auxiliar no equilíbrio quando há deslocamento lateral através do teclado. Mayumi Osada (2009, p.46), 
em sua dissertação The Lister-Sink Method: A Holistic Approach to Injury Preventive Piano Technique, ao expor as ideias da pedagoga norte-americana Barbara Lister-Sink sobre a correta posição do corpo ao piano, relata que o alinhamento ideal das pernas e dos pés não deve ser negligenciado. Dessa forma, os pés não devem ser mantidos no ar, isto é, não devem ficar soltos quando não estiverem em uso. A perna esquerda deve dar suporte para equilibrar o tronco e deve ser usada para contrabalançar o peso quando deslocado.

Ortmann (1929, p.32) não recomendava uma posição fixa das mãos, porque, assim como Kochevitsky (1967, p.40) e Bonpensiere (1953, p.20), acreditava que as mãos seriam moldadas de acordo com o tipo de passagem e ideias musicais a serem executadas. Segundo Ortmann, o ato de tocar implica movimento, não posições predeterminadas. Entretanto, esse notável pesquisador norte-americano expressou sua preferência pelas mãos arqueadas para maior eficiência muscular e vantagem mecânica proporcionada pela mudança do movimento normal do dedo, permitindo que as juntas trabalhassem no âmbito mediano da ação. Bernstein (1981, p.70,153) concorda com Ortmann (1929, p.248) quanto a privilegiar a mão suavemente arqueada. Para verificar, sugeria que se formasse a letra $U$ entre o polegar e o segundo dedo. Para ele, a mão arqueada neste nível médio é ideal porque possibilita que dedos articulados gerenciem a descida e subida da tecla com clareza.

Milanovic (2011c, p.107) afirma que Taubman advoga uma posição neutra e natural da mão. Para obtê-la, deve-se deixar a mão cair naturalmente ao lado do corpo, o que provoca o arqueamento correto, com a nítida presença da união das bases proximais e das pontas distais do metacarpo, sem a quebra de articulações. Essa estratégia proporciona a prática de uma posição bem estruturada dos dedos: nem curvados demais nem estendidos excessivamente. Esse simples ato auxilia no alinhamento de todo o aparato e na construção de uma arquitetura corporal ideal, importante para a otimização dos movimentos executados pelo pianista.

Além disso, Milanovic (2011c, p.138) chama a atenção para o perigo de "twisting", um dos movimentos que produz um elevado grau de tensão no complexo mão/punho/ antebraço e que consiste em flexionar somente a mão em relação ao punho, movendo-a para dentro ou para fora, ou seja, na direção do polegar (desvio radial) ou para longe do antebraço (desvio ulnar). Este hábito encontra severas restrições na visão de Taubman, pois produz tensão indesejada e ocorre, por exemplo, quando o primeiro ou quinto dedo se localiza nas teclas pretas ou em oitavas executadas com o primeiro e quarto dedos, por exemplo. Deve-se, portanto, estar atento ao alinhamento do dedo que toca o antebraço para evitar tais situações ${ }^{10}$.

10 No vídeo Movimentos do punho em 3D, podemos observar os movimentos do punho que fazem a mão em estado de repouso se mover. 


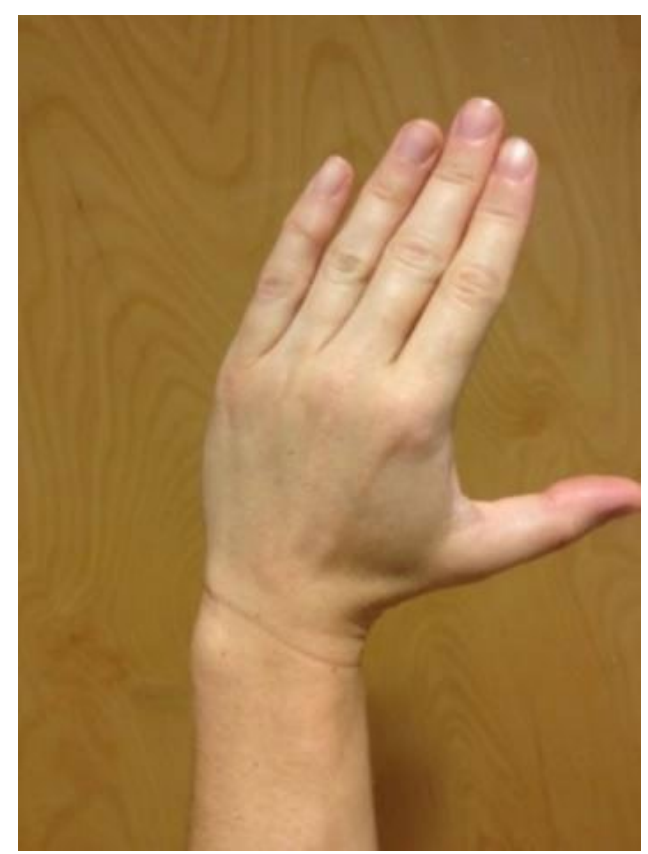

Fig. 1: Desvio radial ${ }^{11}$

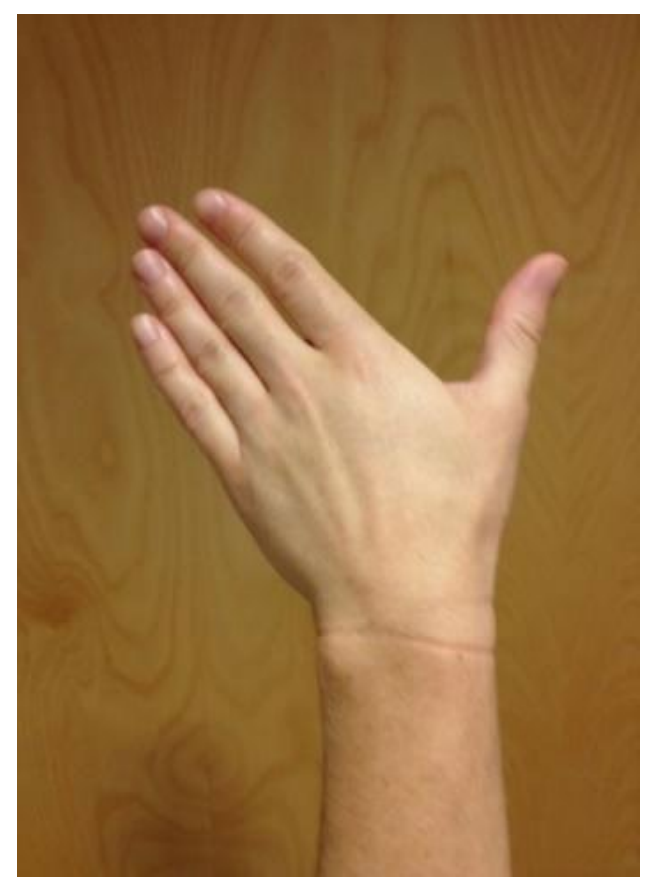

Fig. 2: Desvio ulnar ${ }^{12}$

Mark (2003) acredita que o perigo da torção ou desvio ulnar (twisting) não reside meramente na posição da mão, mas na orientação do polegar, que, como a Fig. 2 mostra, se separa excessivamente do restante dos demais dedos, provocando tensão desnecessária. Entretanto, o autor assume que existem uns poucos pianistas que usam o desvio ulnar sem que haja prejuízo em sua saúde física. Segundo o autor,

11 Disponivel em: https://gymnasticsinjuries.wordpress.com/tag/wrist-pain/.

12 Disponivel em: https://gymnasticsinjuries.wordpress.com/tag/wrist-pain/. 
[...] a posição da mão não é perigosa, é a qualidade de movimento usada para assumir a posição que pode ou não ser perigosa. Se uma pessoa assume uma posição de desvio ulnar da mão usando movimentos orientados para o polegar, que é o que muitos pianistas fazem, então a pessoa está em risco. Mas quando a rotação do antebraço é mapeada corretamente, a mão pode se desviar sem a orientação do polegar. Nesse caso, o desvio ulnar é benigno. Há pianistas que se desviam nas duas direções sem se ferirem. Se uma pessoa se desvia livremente, orientada em torno da ulna, então o desvio a ser usado é uma escolha que a pessoa pode fazer. (MARK, 2003, p.86, tradução nossa). ${ }^{13}$

Torna-se importante reforçar que a manutenção dos braços paralelos ao chão e perpendiculares ao teclado do piano se apresenta como condição primordial para a prevenção da prática indesejada dos desvios de punho descritos acima. O posicionamento sugerido gera uma necessidade constante de ajuste durante a execução, o que permite a preservação da unidade braços, mãos e dedos, funciona como proteção para as alavancas acionadas no movimento e evita, consequentemente, distorções prejudiciais à saúde física do pianista.

Com relação ao toque, a posição dos dedos também foi abordada de várias maneiras. De acordo com sua curvatura no momento em que os dedos são acionados, Matthay (1903, p.34, 35) distingue o clinging touch, ou toque aderente do thrusting touch, ou toque impulsionado. No primeiro, o toque aderente, ideal para passagens em cantabile, usa-se a polpa do dedo, fazendo com que ele fique mais plano. Já no segundo, o toque impulsionado, há um ataque mais vertical e a superfície atingida se torna menor, favorecendo passagens mais brilhantes. Quanto a esta questão, Ortmann (1929, p.217) classificou as posições de acordo com a descida do dedo e com a resistência da tecla. Por exemplo, no flat finger stroke, golpe do dedo plano, há um ganho de velocidade, mas uma perda de força, já que a força é aplicada entre o eixo e a resistência. Justifica-se o seu uso para passagens mais suaves. No curved finger stroke, golpe do dedo curvado, assim como indica o nome, o dedo encontra-se curvado. Nessa posição, uma vez que a resistência está próxima do eixo da alavanca, o efeito da força é maior. No elliptical finger stroke, ou golpe do dedo em elipse, tão preconizado por Taubman, a ponta do dedo entra em contato com o teclado e volta em uma posição diferente da original, mais flexionada. Ao não formar um ângulo reto, distribui-se a força de maneira mais eficiente. Devido ao maior tempo de contato com a tecla, este golpe de dedo pode ser usado para notas repetidas rápidas, mas pode ser empregado também para os pianíssimos, visto que esse contato, derivado de um movimento curvilíneo, favorece um controle mais previsível do som e ainda evita a tensão excessiva.

Convém salientar também que os dedos não devem permanecer excessivamente curvados, como se estivessem sendo enrolados para o interior da palma da mão. No vídeo Finger use: curling versus curving (2008), Edna Golandsky, discípula de Dorothy

13 Original: "[...] the position of the hand is not what is dangerous, it is the quality of movement used to assume the position that may not be dangerous. If a person assumes an ulnar-deviated position of the hand using thumb-oriented movements, which many pianists do, then the person is at risk. But when forearm rotation is properly mapped, the hand can deviate without thumb orientation. In that case ulnar deviation is benign. There are pianists who deviate in both directions without injury. If a person deviates freely, oriented around the ulna, then the deviation to use is a choice the person can make" (MARK, 2003, p.86). 
Taubman, atenta para o perigo desse exagero na flexão dos dedos, pois se utiliza a ação dos flexores profundos e se cria tensão em excesso, o que pode, eventualmente, causar lesões.

Para Mark (2003, p.107), assim como para Taubman, quando deixamos nossas mãos caírem livremente ao lado do corpo, os dedos assumem uma posição levemente curvada. Segundo o autor, essa posição é a mais eficiente, pois não há um esforço muscular no sentido de ajustá-los.

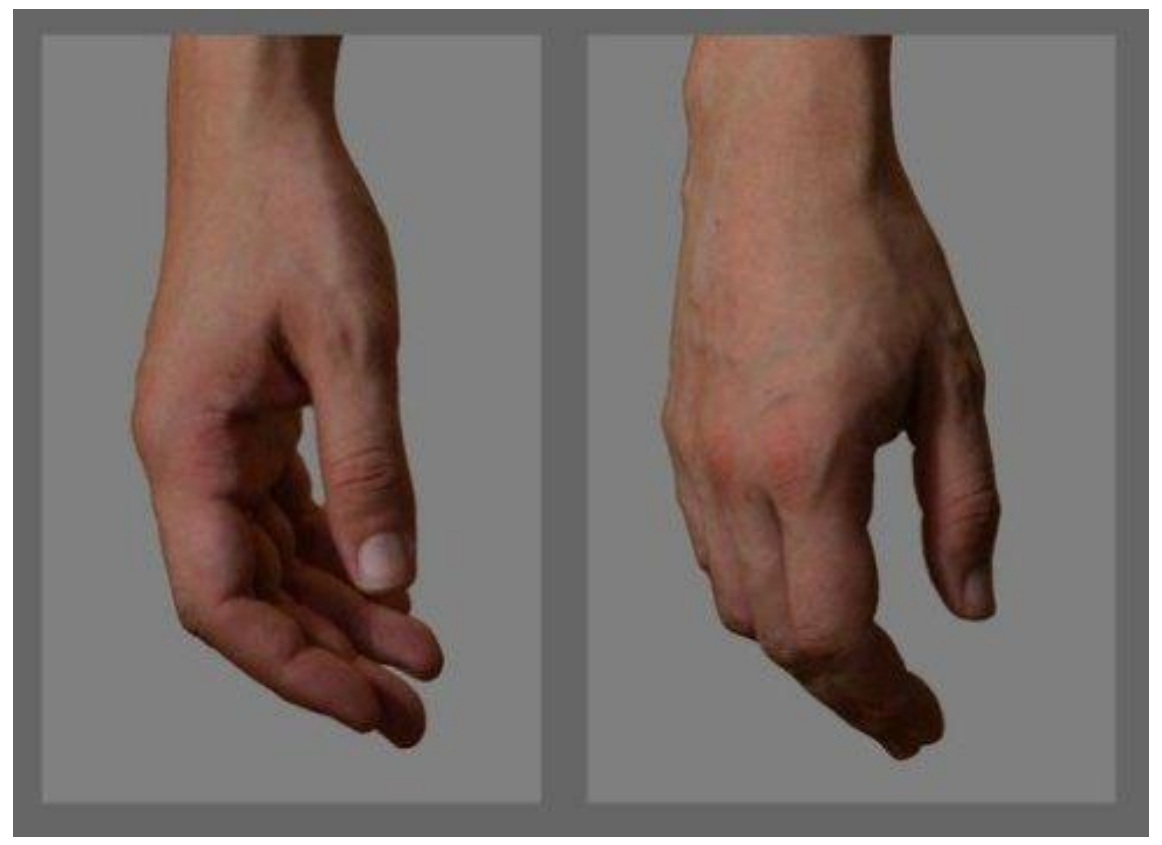

Fig. 3: Curva natural dos dedos ${ }^{14}$

Entretanto, muitas vezes nota-se o dobramento das duas articulações finais dos dedos de maneira mais proeminente, o que produz uma curva mais acentuada que a natural. Mark (2003, p.107) justifica a inadequação desse movimento de contração conjunta. Segundo o autor, quando enrolamos as duas últimas articulações em direção à palma da mão, os músculos flexores da parte inferior do antebraço são contraídos. A ação de levantar os dedos provoca, por sua vez, a contração dos músculos extensores da parte superior do antebraço. Portanto, se levantarmos os dedos mantendo a curvatura proeminente, usaremos os músculos flexores em oposição ativa aos músculos extensores. Além disso, a referida curvatura excessiva provoca o encurtamento e a compressão do punho, que perde sua estrutura longa e flexível e assume uma forma de dobradiça. Isso pode levar à tendência de tocar com o punho baixo, o que para Taubman também é uma fonte de tensão e uma barreira na transmissão da energia entre o antebraço e os dedos. Segundo a autora, o uso dessa posição faz com que o peso do braço caia sobre o punho, causando dores e desconforto.

No artigo "Healthy virtuosity with the Taubman approach", Therese Milanovic

14 Disponivel em: https://klpianist.files.wordpress.com/2013/10/hands-relax-set-1.jpg. 
(2011a, p.11) aponta que Taubman, contrariando Ortmann (1929, p.32) e sua sugestão de uma mão alinhada em ângulo reto com o antebraço, recomenda que o quinto dedo esteja alinhado com o cotovelo e que o indicador mantenha uma inclinação de quinze graus em relação ao antebraço.

Milanovic (2011c, p.141) atenta também para o "Keybedding", ou seja, a sensação de pressionar o fundo da tecla, um termo utilizado pela primeira vez por Matthay (1947, p.88). Se aplicado com excessiva força depois de ter atingido o escapamento ou ponto de produção do som, o resultado mostra um som duro e um corpo tensionado que, a despeito da força empregada no ataque, não gera qualquer modificação do som produzido. Matthay (1947, p.95), entretanto, não é contra uma leve pressão usada apenas para dar segurança e sentir o teclado, e, segundo Chiantore (2001, p.453), Busoni acredita que sentir o fundo da tecla nos pontos de apoio é fundamental para executar cada gesto pianístico, especialmente nos pianos mais pesados do final do século XIX. Já para Taubman, o desequilíbrio de energia gerado pela excessiva pressão do fundo da tecla representa um grave impedimento para o desenvolvimento de uma técnica saudável e livre de tensão desnecessária. Segundo sua abordagem, esse mecanismo está associado a dores na parte inferior do antebraço, trata-se de um mau hábito que pode causar lesões graves. Apesar da sensação ilusória de maior expressividade e envolvimento emocional, o resultado sonoro não corresponde ao esforço despendido. Paradoxalmente, este tipo de toque contribui para significativas limitações de velocidade e de controle do som obtido. Para que isso não aconteça, a autora sugere o domínio do ponto exato de produção do som, ou seja, o domínio da zona de escape da tecla do piano, na qual o martelo é acionado para atingir as cordas, perdendo momentaneamente o seu contato com o resto do mecanismo. O ponto de produção do som no piano está localizado ligeiramente mais próximo do fundo da tecla do que da sua superfície e pode ser sentido como uma pequena resistência no mecanismo do teclado. Nessa exata posição, a tecla atingirá o ponto de som antes de chegar ao fundo. Como o som é produzido nesse ponto, nada ocorrerá após seu acionamento em relação ao som já gerado. Uma vez que o som é acionado, apertar a tecla não produz qualquer resultado no som, mas pode causar danos no físico de quem toca.

Segundo Mark (2003, p.128-130), tanto a quantidade quanto a qualidade do som estão relacionadas à velocidade de descida da tecla, e não somente à força exercida sobre a mesma. Dessa maneira, quanto mais rápida a descida, maior o volume sonoro e diferente será a relação de seus harmônicos em comparação a um abaixamento mais lento, por exemplo. O autor também destaca a importância da interação tátil, principalmente da polpa dos dedos com o teclado, função essencial para o desenvolvimento do relacionamento com a tecla e, consequentemente, do controle do ponto de som.

Lister-Sink (2005), na segunda parte de seu DVD Freeing the caged bird: Potentially Harmful Technical Habits, mostra o quão pouco peso é necessário para se manter uma tecla para baixo, refutando, assim como Taubman, a prática de se pressionar o fundo da tecla com esforço. A consciência do mecanismo do piano, do escapamento e do ponto da produção do som na tecla faz com que o artista melhore o seu relacionamento com a descida e o rebote da tecla. Assim, por exemplo, a consciência do mecanismo da tecla 
pode ajudar a criar um efeito de legato em acordes repetidos, golpeando novamente a tecla antes de sua subida. Esse aspecto tão indispensável na execução de obras de grande porte foi descrito primeiramente por Matthay (1932, p.7, 9) e depois por Taubman, que aplicou o termo riding the key, a ser entendido como "cavalgando a tecla". 0 mesmo movimento ou golpe atua na sensação do rebote na execução dos staccati. É importante também no controle da dinâmica - já que, quanto maior a velocidade da descida, mais intensidade e volume de som se produzirão e vice-versa - e no controle da qualidade do som, visto que, quanto mais gradual, mais belo e agradável será o resultado obtido. Kochevitsky (1967, p.25) descreve o exercício de sensibilidade pensado para desenvolver essa coordenação, que consiste em abaixar a tecla em pianíssimo e sentir seu levantamento não pelo uso da ação muscular, mas como se houvesse uma desistência da sua aplicação e seu efeito. Cremos que esta concepção faz sentido porque o som é produzido na descida da tecla e, mais raramente, na subida. Via de regra, o controle da subida precisa ser conjugado com o uso do pedal de acordo com a intenção sonora desejada. Em acréscimo, a liberação das teclas está diretamente relacionada à coordenação de sutis nuances de impunho e soltura da engrenagem formada por dedos-mão-punho-antebraço-braço.

O polegar desempenha um papel crucial na aplicação de uma técnica saudável e eficiente. O seu uso incorreto constitui uma das causas de tensões excessivas e dificuldades na execução e compreensão de passagens, sejam elas complexas ou simples. Sua fixação pode afetar o funcionamento dos outros dedos e limitar a mobilidade de mãos e braços. Taubman chama a atenção para o fato de que o polegar se diferencia dos outros dedos tanto pela sua posição na mão quanto pelo seu formato e função na técnica pianística. Os músculos que controlam os movimentos verticais desse dedo são menos efetivos do que aqueles que controlam o deslocamento lateral e rotacional do braço. De acordo com Mark (2003, p.105), a maioria dos músculos que move a mão e os dedos está no antebraço, não nos dedos. Assim, movê-lo isoladamente, utilizando apenas a sua movimentação vertical, demonstra uma maneira ineficiente de abordar sua funcionalidade. Entretanto, quando o movimento vertical do polegar é integrado à rotação do antebraço, estabelece-se outra qualidade de disponibilidade, permitindo consequentemente uma maior facilidade na execução, além de proporcionar segurança e solidez no toque, visto que sua ação será apoiada por todo o sistema coordenado dedo-mão-antebraço.

A associação benéfica entre o movimento vertical do polegar, a rotação e o suporte do antebraço foi descrita por Thomas Mark (2003):

Embora o polegar se mova principalmente da articulação carpometacárpica, ele não se move isoladamente do resto do braço quando tocamos piano. Quando o polegar é usado com eficiência, recebe apoio de todo o antebraço através do arco do antebraço. Pode haver uma ligeira sensação de inclinação ou rotação no antebraço ao tocar o polegar para distribuir o esforço por todo o antebraço, dando uma sensação de estabilidade praticamente sem esforço. O conhecimento da mecânica da rotação do antebraço garante que o leve apoio rotacional do polegar não leve à orientação do polegar. O polegar pode permanecer muito 
livre, com os músculos ao redor soltos. ${ }^{15}$ (MARK, 2003, p.96, tradução nossa).

Thomas Mark destaca ainda que o movimento do polegar deve iniciar na articulação carpometacárpica, não na articulação metacarpofalangeana.

Se você estiver usando todo o seu polegar, que inclui três articulações, você sentirá uma relação segura e confortável com o instrumento. Se você está supondo que o polegar tem dois ossos em vez de três, você sofrerá de restrição de movimento na articulação carpometacárpica do polegar, mais próxima do punho, excesso de proeminência na articulação metacarpofalangeana, e provavelmente dor também. (MARK, 2003, p.95, tradução nossa). ${ }^{16}$

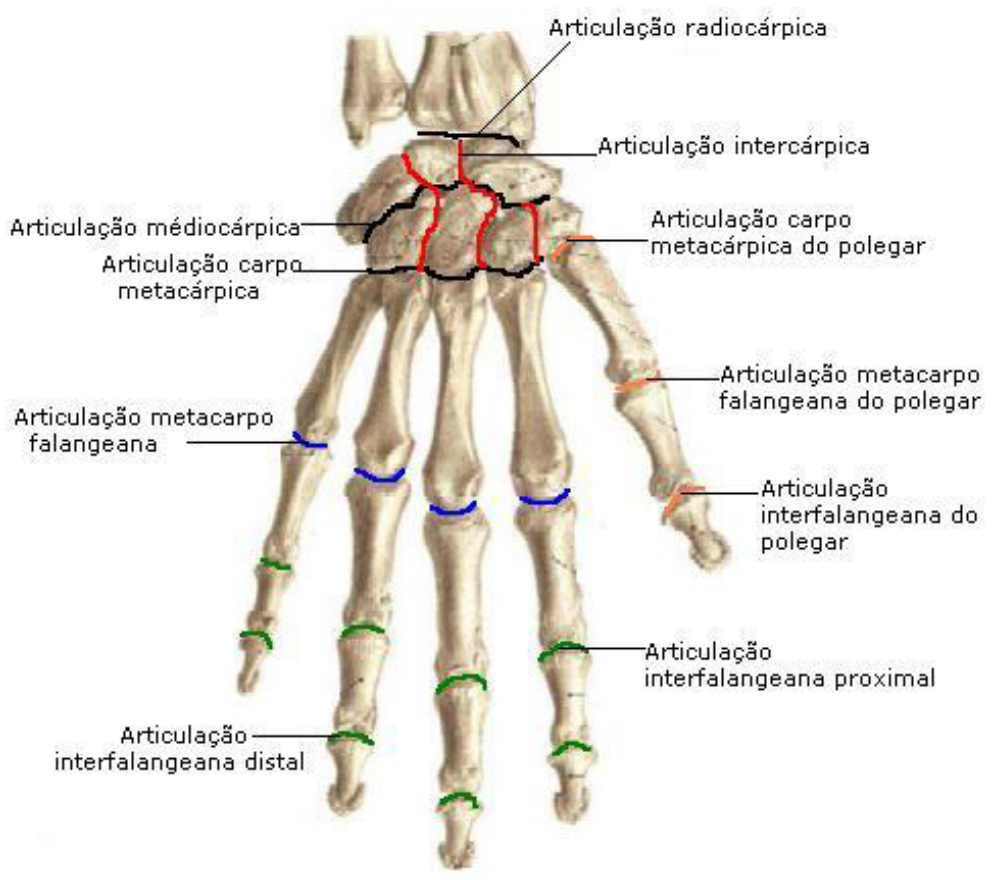

Fig. 4: Articulação do polegar: anatomia da mão

Os autores citados tendem a enfatizar que a manutenção de uma postura equilibrada e consciente promove movimentos saudáveis e coordenados, constituindo assim condição essencial para a o desenvolvimento pianístico.

\section{a) Coordenação dos movimentos}

\footnotetext{
15 Original: "Although the thumb moves principally from the CMC joint, it does not move in isolation from the rest of the arm when we play the piano. When the thumb is efficiently used it receives support from the entire forearm through the forearm arch. There can be a very slight feeling of tilting or rotation in the forearm in the playing of the thumb to distribute the effort across the entire forearm, giving a sense of stability with virtually no effort. Knowledge of the mechanics of forearm rotation ensures that the slight rotational support for the thumb does not lead to thumb orientation. The thumb can remain very free, with the muscles around it loose" (MARK, 2003, p.96).

16 Original: "If you are using your whole thumb, one that includes three joints, you will feel a secure and comfortable relationship with the instrument. If you are assuming that the thumb is two bones instead of three, you will suffer from restricted movement at the CMC joint, nearest the wrist, and over-prominence at the MCP joint, and probably soreness as well" (MARK, 2003, p.95).
} 
A coordenação dos movimentos representa, sem dúvida, uma concepção que fez com que a compreensão dos requisitos necessários para a execução pianística desse um grande salto no sentido de atingir uma maneira mais racional e saudável de tocar. Segundo Gerig (2007, p.256), Deppe, já na segunda metade do século XIX, em consonância com os avanços do conhecimento da fisiologia, descreve o conceito de sinergia muscular. De acordo com seu pensamento, os músculos não agem independentemente, mas coordenados com um ritmo. Assim, o autor enfatiza a necessidade da coordenação de diversos seguimentos do corpo, excluindo a ideia de isolamento de suas partes. Marcel Bienfait (2000, p.29, 30), estudioso de fisiologia moderna, afirma que, na região de cada eixo articular, dois movimentos são possíveis em direções diametralmente opostas: a flexão ou a extensão, a abdução ou a adução, a rotação interna ou a externa. Segundo o autor, a regulação do movimento se origina desse antagonismo. Dessa maneira, quando um grupo de músculos realiza o movimento desejado, o grupo antagonista o controla freando sua violência, limitando sua velocidade, regulando sua amplitude e conferindo precisão. No entanto, esse controle não se limita ao sistema antagonista. Bienfait defende que esse sistema intervém por meio de músculos laterais para dirigir o movimento, ou por músculos antifuncionais para limitar a ação. Seguindo esse raciocínio, para o fisiologista não existem músculos antagonistas, mas complementares. Dois músculos seriam sinérgicos quando se aliam para um objetivo comum, mesmo tendo, inicialmente, funções diferentes. Não existe, portanto, músculo de função única. $O$ estudioso francês defende que os complexos musculares apresentam em seu vetor de tração uma obliquidade que faz com que seja um flexor e rotador interno, e outro flexor e rotador externo. Não há, portanto, ação de um músculo isolado, mas, sim, sinergias de cadeias musculares.

Essa ideia nos leva à discussão da relação entre contração e distensão muscular. A defesa de apenas um conceito em detrimento do outro é vista de forma negativa por vários autores. $O$ excesso de contração foi considerado contraproducente por Taubman. Mark (2003, p.141) afirma que a situação em que os músculos opostos são ativados ineficientemente de maneira a requerer tanto a flexão quanto a extensão em direções opostas e simultâneas ao redor de uma articulação, a contração conjunta inibe o movimento e pode causar lesões. Essa dupla tração acontece quando, por exemplo, há uma fixação do braço na tentativa de mover os dedos rapidamente ou na tensão no polegar tão comum quanto nefasta na execução de oitavas. A falha na distensão de um dos músculos pode levar ao excesso de tensão e, consequentemente, à fadiga e a uma execução ineficaz e pouco saudável dos movimentos. Fraser $(2011$, p.36) acredita que a contração é essencial para a realização de qualquer movimento, mas que pode ser prejudicial caso não seja equilibrada, ou seja, coordenada. Ele define uma contração como não saudável quando o grau de antagonismo é muito alto e o resultado é excesso de tensão. De fato, a experiência comprova que a tensão restringe os movimentos, o equilíbrio disponibiliza a energia necessária para a execução dos movimentos.

Em relação ao conceito de relaxamento ou soltura, como mais comumente se diz no Brasil, Ortmann defende que "O excessivo relaxamento é pesado e traz dificuldade 
de velocidade"17 (ORTMANN, 1929, p.125, tradução nossa). O autor expressa suas preocupações e, ao condenar maus hábitos, esclarece que tanto o hiporrelaxamento, quando um conjunto de músculos antagônicos relaxa numa taxa mais lenta que o outro contrai, causando tensão, quanto o hiper-relaxamento, quando um conjunto relaxa mais rápido que o outro contrai, são nocivos. Sobre o momento oportuno para a contração, Ortmann (1929, p.122) defende que seja antes ou no instante de introduzir a resistência que o músculo deve vencer, especialmente no andamento rápido, pela dificuldade em superar a inércia. $O$ distensionamento deve ser tão imediatamente posterior à produção do som quanto possível, mas não pode existir durante a própria realização. Kochevitsky (1967), ao comparar com a escola de dedos a escola anatomofisiológica, que, segundo ele, cultuava o excesso de soltura, aborda esta questão e afirma que "a ideia de relaxamento trouxe consigo outro perigo, o da fraqueza e frouxidão" (KOCHEVITSKY, 1967, p.9, tradução nossa). ${ }^{18} \mathrm{O}$ próprio termo é tão controverso que vários autores preferiram substituí-lo por outros vocábulos, como quietude efetiva (FRASER, 2011, p.32), elasticidade (GAT, 1980, p.85) ou mesmo soltura. A solução seria, portanto, uma constante busca ou ajuste do equilíbrio entre relaxamento e contração e o uso do aparato esquelético-muscular com uma unidade, não como segmentos isolados e fragmentados. Neste sentido, recomenda-se aliar o sentido de equilíbrio do braço, antebraço e mão com um direcionamento de energia coordenada do corpo para o teclado.

Matthay (1947, p.114, 115) já nos oferece uma ideia da integração entre as várias partes do corpo e a combinação entre peso e atividade muscular quando descreve as três espécies de formação do ataque. O finger exertion, ou esforço dos dedos, consiste na ação digital com o braço e a mão em repouso. No finger and hand exertion, esforço dos dedos e da mão, combina-se a ação dos dedos com a mão, e no arm weight, peso do braço, todo o conjunto entra em ação: dedo, mão e peso do braço. O segundo tipo de coordenação descrito por este pedagogo é imprescindível para a execução, por exemplo, do legato. Além da consciência aural e da expressiva entonação, para sua realização combinam-se a atividade do dedo, sua sensibilidade com o teclado e o uso da transferência do peso do braço, especialmente em passagens lentas. Nota-se que o peso não constitui um substituto para a atividade digital e também não representa a única maneira de provocar o ataque na tecla e sua descida.

Ortmann (1929) é um defensor da coordenação dos movimentos, a fim produzir o mínimo de esforço e o máximo de resultado com precisão e liberdade. Segundo ele, "no movimento coordenado, cada parte deve atuar na sua melhor vantagem mecânica" (ORTMANN, 1929, p.114, tradução nossa). ${ }^{19}$ Dessa forma, músculos e articulações menores são responsáveis por movimentos de menor amplitude e maior velocidade. Já segmentos maiores se encarregam dos movimentos de maior força e poder. Em autores mais recentes, como Fink (1992, p.41) e Mark (2003, p.2, 3), bem como na experiência de Taubman, deparamo-nos com este conceito essencial, qual seja, dedos, mãos e braços

17 Original: "Excessive relaxation is heavy, rendering speed difficult" (ORTMANN, 1929, p.125).

18 Original: "[...] the idea of relaxation brought with it another danger, that of weakness and looseness" (KOCHEVITSKY, 1967, p.9).

19 Original: "[...] In coordinate movement, each part must act at the best mechanical advantage" (ORTMANN, 1929, p.114). 
devem operar como uma unidade sincronizada, condição que consideramos primordial para o estabelecimento de uma técnica eficiente e saudável.

Entretanto, Ortmann (1929, p.48) atenta para o fato de que a ausência de movimento não garante inatividade do músculo e que a simplicidade visual de um movimento pode não corresponder à simplicidade da atividade muscular exercida. Esse ponto de vista encontra respaldo em Lister-Sink (2000), que, além do problema da incerteza da aparência, observa as dificuldades de se descreverem as sensações físicas:

A técnica é, em primeiro lugar, uma experiência física, cinestésica. Como, então, uma descrição ou definição escrita da técnica pode servir para ensinar uma experiência extremamente física? Podemos descrever poética ou cientificamente as sensações cinestésicas do balançar de golfe, o cheiro de uma rosa, o sabor de um morango ou a textura de veludo, mas a experiência real de cada um desafia a descrição por meio das palavras. E é a experiência das sensações físicas que precisamos comunicar no ensino da técnica. (SPRING 2000, p.16, tradução nossa). ${ }^{20}$

Outra discussão pertinente quando se trata de coordenação de movimentos constitui a questão da independência dos dedos. Segundo Torres (2017, p.118), Maria Levinskaya advoga que a ação digital é essencial, desde que associada à participação do braço. Para Levinskaya, o fato de a independência dos dedos ser fisiologicamente impossível pelo fato de os músculos flexores estarem situados na mão e no antebraço não significa que ela não possa ser idealizada ou mesmo desejada. Mark (2003) também discorre sobre essa impossibilidade. De acordo com o autor,

Não há músculos nos dedos, embora os pequenos músculos da mão alcancem a articulação metacarpofalangeana para estender os dedos, juntá-los e dobrá-los na articulação metacarpofalangeana (estes são os músculos interósseos ou "entre os ossos" que se encontram entre os metacarpos). Os músculos da mão também contribuem para o movimento do polegar. Mas a maioria dos movimentos da mão e dos dedos é realizada a partir dos músculos do antebraço. ${ }^{21}$ (MARK, 2003, p.105, tradução nossa).

De acordo com Torres (2017, p.205), Levinskaya acrescenta ainda sua oposição à ideia de uma atividade digital baseada no relaxamento máximo dos músculos que não participam do movimento. Segundo a autora, músculos que não participam diretamente do movimento também não estarão completamente relaxados, mas, sim, em um estado de controle absoluto. Levinskaya entende a independência como "a flexão deliberada desde a articulação do dedo, evitando que outras partes do braço se movam involuntariamente" (TORRES, 2017, p.205 apud LEVINSKAYA, 1930, p.159, tradução nos-

\footnotetext{
20 Original: "Technique is, first and foremost, a physical, kinesthetic experience. How, then, could a written description or definition of technique serve to teach a very physical experience? We may describe poetically or scientifically the kinesthetic sensations of a golf swing, the smell of a rose, the taste of a strawberry, or the texture of velvet, but the actual experience of each defies description through words. And it is the experience of the physical sensations that we need to communicate in teaching technique" (SPRING, 2000, p.16).

21 Original: "There are no muscles in the fingers, although the small muscles in the hand do reach across the MCP joint to spread the fingers, them back together, and bend them at the MCP joint (these are the interosseous or 'between the bones' muscles, which lie between the metacarpals). Hand muscles also contribute to movement of the thumb. But most movements of the hand and fingers are accomplished by muscles in the forearm" (MARK, 2003, p. 105).
} 
sa). ${ }^{22}$ Sempre lembrando que os dedos não podem se tornar independentes da ação de outros músculos, voluntária ou involuntariamente, Levinskaya propõe o seguinte diagrama, que mostra os músculos que colaboram com a ação dos dedos:

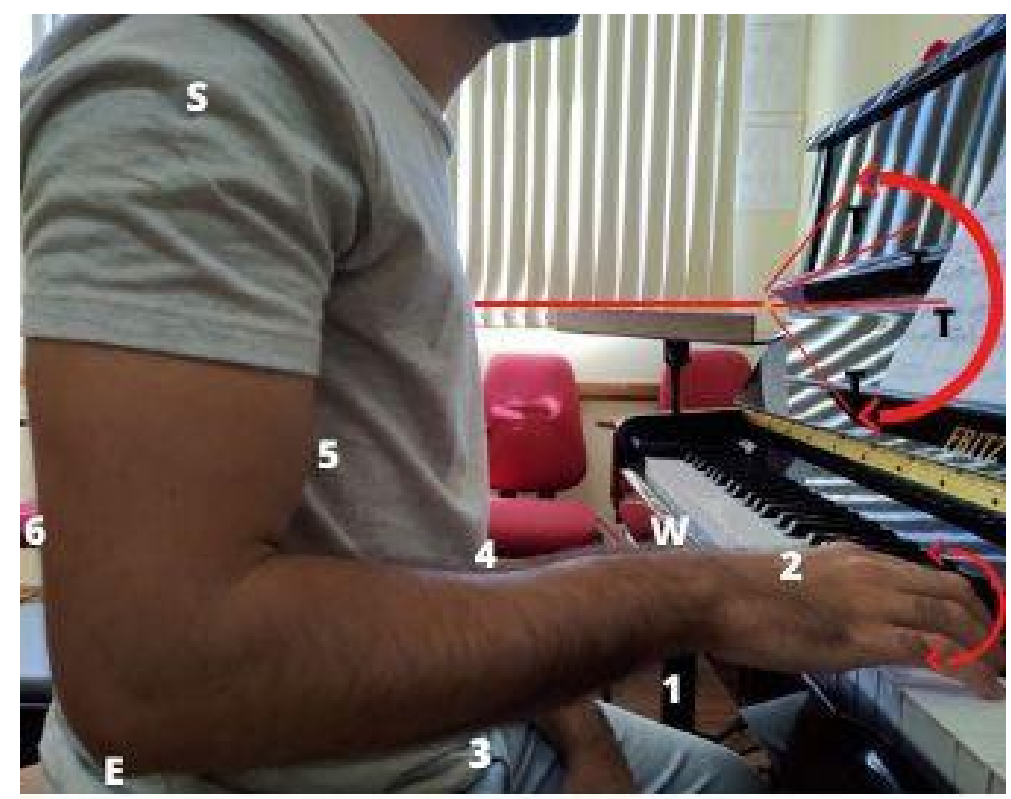

Fig. 5: Músculos implicados nos movimentos dos dedos, segundo Levinskaya. Fonte: Torres (2017, p.206 apud LEVINSKAYA, 1930, p.160).

1: flexores (lumbricais)

2: extensores (interósseos)

3: flexores

4: extensores.

5: [bíceps] para manter em repouso o antebraço e o cotovelo

6: [dorsais] para manter o braço perto do corpo

S: ombro

E: cotovelo

W: punho

Para Mark (2003), os dedos não devem ser responsáveis por iniciar o movimento, mas são importantes receptores táteis. Ainda segundo Mark,

É uma surpresa para a maioria dos pianistas que não há músculos nos dedos. Mas não é de surpreender que devamos estar mais conscientes dos nossos dedos que dos músculos que os movem. Nossos receptores sensoriais cinestésicos são projetados para nos informar do movimento, não das causas do movimento. No entanto, o fato de os músculos que movem os dedos estarem distantes dos 
dedos é muito importante. ${ }^{23}$ (MARK, 2003, p.105, tradução nossa).

Não é demais reiterar que, para Taubman, dedos, mão e antebraço devem trabalhar coordenadamente, como uma unidade. Assim como Levinskaya, a pedagoga americana defende que isso não significa que os dedos não devam estar ativos, mas não devem trabalhar isoladamente. A sincronia do movimento de todas as partes proporciona não só o conforto físico, mas o virtuosismo saudável, o aumento da palheta sonora, a melhor interação com o teclado e, consequentemente, uma melhor realização das ideias musicais.

Vale ressaltar que a busca do virtuosismo saudável representa uma constante na abordagem Taubman. Uma de suas maiores contribuições foi atentar para a existência de enfermidades com elevada prevalência entre os pianistas, tais como tendinites e distonias focais. Ao longo de sua trajetória, a pedagoga foi desenvolvendo, testando e empregando categorias de movimentos saudáveis como alternativas viáveis para pianistas incapacitados por hábitos errôneos de estudo e que levam à fadiga, dor e incapacitação. Segundo Milanovic (2011c, p.8), para Taubman, os movimentos coordenados são terapêuticos, e são esses movimentos, não o desenvolvimento muscular, os responsáveis por produzir uma boa técnica. Ao enfatizar a gratificação de uma performance bem conduzida em todos os aspectos, a autora aponta para a necessidade de realizar o diagnóstico dos entraves apresentados por incompreensão e/ou maus hábitos e, descobrindo as causas, reeducar para um novo patamar de competência pianística com movimentos coordenados e saudáveis.

\section{b) Função do braço}

O tão célebre peso do braço tem sido discutido por vários pedagogos. No artigo "The Taubman Approach to Piano Technique: What it is and What it isn't", Milanovic (2011b, p.6) defende que, na abordagem Taubman, o peso só será direcionado do braço para a ponta dos dedos e transporá a resistência do teclado se as unidades antebraço, mão e dedos estiverem coordenadas. Matthay (1932, p.59) também acredita na completa integração, afirmando que o braço serve como base para a ação dos dedos e da mão. Fraser $(2011$, p.40, 41) atenta para a importância da atividade muscular, que é responsável pelo controle da massa do braço, mesmo que o movimento seja obtido em conjunção com a gravidade. Para ele, esse trabalho dos músculos e a integridade do esqueleto devem estar em posição de prevalência em relação ao peso do braço. Pode-se perceber um consenso entre vários autores, tais como Ortmann (1929, p.150) e Fraser (2011, p.38), quanto à assim denominada queda livre. Para esses autores, trata-se de um conceito errôneo e desaconselhável. Ortmann esclarece que essa queda é descontrolada e que, apesar de um momentâneo benefício de aprendizagem no con-

23 Original: "That there are no muscles in the fingers comes as a surprise to most pianists. But it is not surprising that we should be more aware of our fingers than we are of the muscles that move them. Our kinesthetic sense receptors are designed to inform us of movement, not the causes of movement. Nevertheless, the fact that the muscles that move the fingers are distant from the fingers is very important" (MARK, 2003, p.105). 
trole da unidade antebraço, braço, mão e dedos e da sensação de distensão, o conceito de queda livre pode contribuir para o entendimento equivocado do funcionamento do mecanismo pianístico. Fraser, por sua vez, afirma que, para a criação de uma variedade sonora pianística mais ampla, se deve objetivar não uma liberdade proporcionada por uma queda descontrolada, mas uma liberdade capacitante, obtida por meio da ativação muscular do braço.

Em seu trabalho, Levinskaya (1930) dedica atenção especial a diferentes situações musculares do braço. Segundo Torres (2017, p.166), para a pedagoga de origem russa, esses estados exercem um papel determinante na produção dos diferentes efeitos sonoros alcançados no piano, das gradações de força à maior delicadeza de som, que se relacionam com as sensações de relaxamento, rigidez, elasticidade, rigidez voluntária, tensão de contração e liberação dos músculos. Dessa forma, cada alteração muscular produz uma mudança sonora. Em outras palavras, as variações no colorido sonoro estão intimamente ligadas às sensações musculares do braço e aos seus movimentos. De acordo com Torres, (TORRES, 2017, p.166 apud LEVINSKAYA, 1930, p.95, tradução nossa), Levinskaya propõe a seguinte esquematização desses estados:

1. Estado não natural de tensão extrema indesejável - rigidez, cãibras

2. Estado indesejável de relaxamento extremo, descanso e inatividade - relaxamento, preguiça

3. Estado desejável de atividade potencial - liberdade, flexibilidade, relaxamento parcial, liberação de movimento

4. Estado de prontidão para o movimento imediato - elasticidade, leveza, resistência, fluidez

5. Status da atividade - esforço, contração, tensão (dos músculos)

6. Efeitos resultantes da atividade - firmeza, rigidez voluntária, fixação, estabilização (de várias partes do corpo). (TORRES, 2017, p.166 apud LEVINSKAYA, 1930, p.95, tradução nossa). ${ }^{24}$

Notamos, portanto, que o braço participa da atividade pianística tanto pela liberação de seu peso em um estado parcial de relaxamento quanto de tensão muscular voluntária, controlada e momentânea. Segundo Torres (2017, p.185), Levinskaya discute o conceito de fixação e afirma que este se encontra intimamente ligado ao desenvolvimento do controle muscular. Consiste na capacidade de contrair os músculos requeridos no momento exato, assim como de isolar aqueles desnecessários e liberá-los instantaneamente após a contração. A capacidade de direcionar a energia para o

24 Original: "1. Estado no natural de extrema tensión indeseable - rigidez, calambres.

2. Estado indeseable de relajación extrema, descanso e inactividad - relajación, flojedad, flojera.

3. Estado deseable de actividad potencial - libertad, flexibilidad, relajación parcial, liberación del movimiento. 4. Estado de preparación para el movimiento inmediato - elasticidad, ligereza, resistencia, flotabilidad.

5. Estado de actividad - esfuerzo, contracción, tensión (de los músculos)

6. Efectos resultantes de la actividad - firmeza, rigidez voluntaria, fijación, estabilización (de diversas partes del brazo)" (TORRES, 2017, p.166 apud LEVINSKAYA, 1930, p.95). 
ponto onde é requerida, isto é, do braço para os dedos, sem quebras ou empecilhos, representa uma capacidade essencial para o desenvolvimento técnico do pianista. Para Levinskaya, não se deve confundir essa fixação instantânea com aquela permanente, causadora de dores e rigidez desnecessária. Partindo desse conceito e com o intuito de evitar essa tensão indesejada, Torres afirma que Levinskaya relaciona o funcionamento do sistema muscular do braço, antebraço, punho, mãos e dedos a um sistema de alavancas. $O$ principal ponto de referência em uma alavanca constitui seu ponto de apoio, conhecido por fulcro, que deve ser estabilizado artificialmente por meio de nossa vontade. Nas palavras de Levinskaya, deve-se "criar uma base firme para suas operações, harmonizando voluntariamente uma parte (o osso) com a contração muscular para mantê-lo em posição. Essa rigidez voluntária em uma parte da alavanca, enquanto a outra parte da alavanca pode se mover livremente, é chamada de fixação" (TORRES, 2017, p.186 apud LEVINSKAYA, 1930, p.122, tradução nossa). ${ }^{25}$ Segundo Torres (2017), de acordo com a abordagem de Levinskaya, o braço pode também formar outra alavanca com o antebraço, a mão e o dedo. Dessa forma, cada alavanca pode operar independentemente ou fazer parte de uma alavanca maior e deslocar-se junto com a mesma. Assim, uma alavanca pode ficar fixa enquanto outras se movem, estabilizando o movimento das demais, como no ataque de cotovelo proposto pela autora:

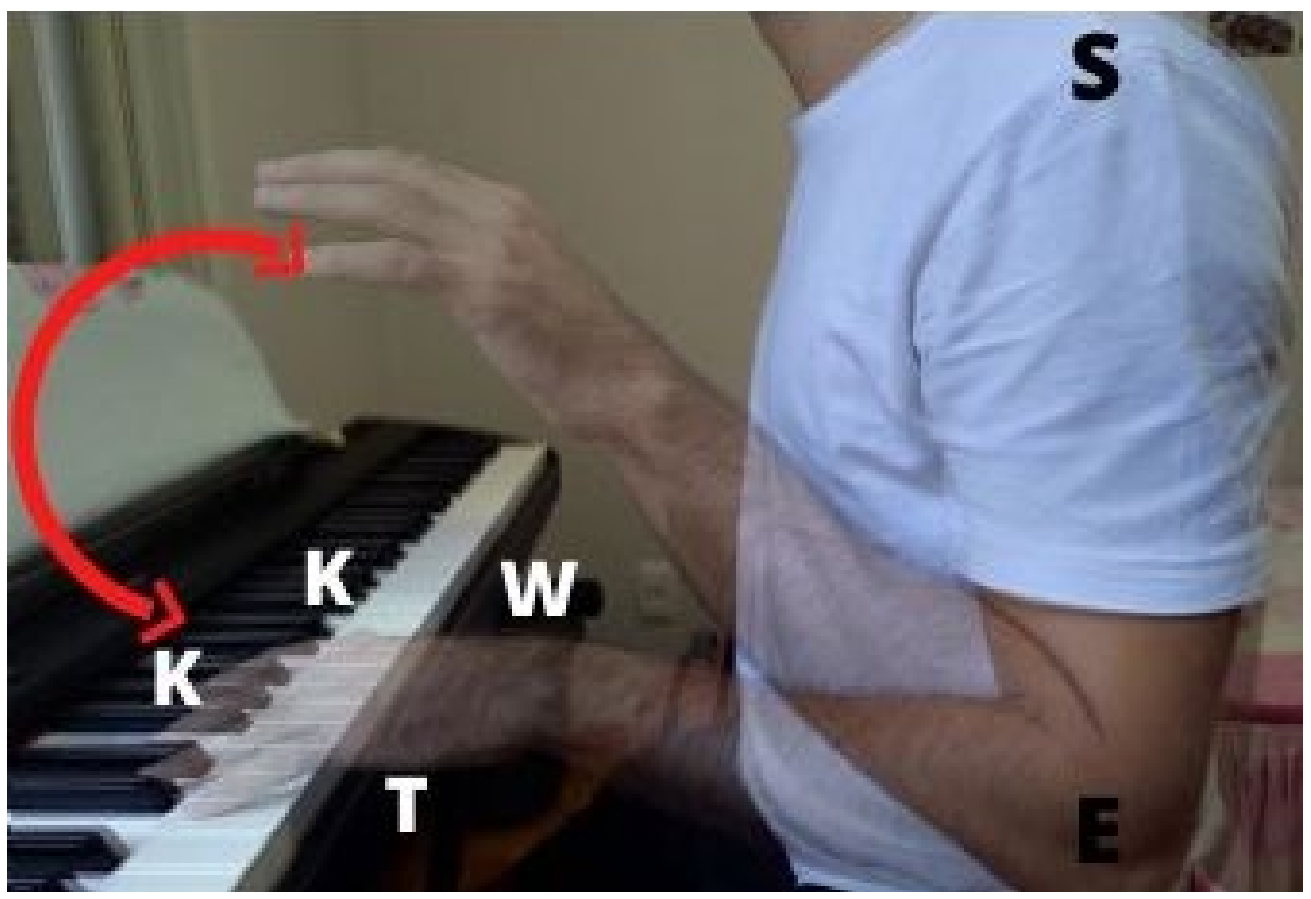

Fig. 6: $O$ ataque de cotovelo, segundo Levinskaya. S-E (do ombro até o cotovelo) é uma parte fixa. E-T (do cotovelo até a ponta do dedo) é a alavanca. Isso não significa, entretanto, que S-E deve ser rígido. Ao contrário, deve ser livre para mover-se tão logo seja acionado. O cotovelo será o eixo. Fonte: Torres (2007, p.186 apud LEVINSKAYA, 1930, p.122).

25 Original: "[...] crear una base firme para sus operaciones, fijando voluntariamente una parte (el hueso) con la contracción muscular para mantenerlo en su posición. Esta rigidez voluntaria sobre una parte de la palanca mientras la otra parte de la palanca puede moverse libremente es Ilamada 'fijación'" (TORRES, 2017, p.186 apud LEVINSKAYA, 1930, p.122 


\section{c) Rotação}

A rotação, que consiste no giro da unidade antebraço, mão e dedos, permite que os dedos trabalhem sem esforço excessivo e sejam auxiliados pela ação do antebraço e da mão, a fim de abaixar a tecla. A rotação pode ser conseguida por movimentos de pronação ou supinação. Na pronação há um giro do antebraço em direção ao polegar, de modo que a palma da mão fique voltada para baixo. Já no movimento oposto, a supinação, o giro é realizado para fora em direção ao quinto dedo, de maneira que a palma fique voltada para cima. A Fig. 7 representa os movimentos de pronação e supinação.

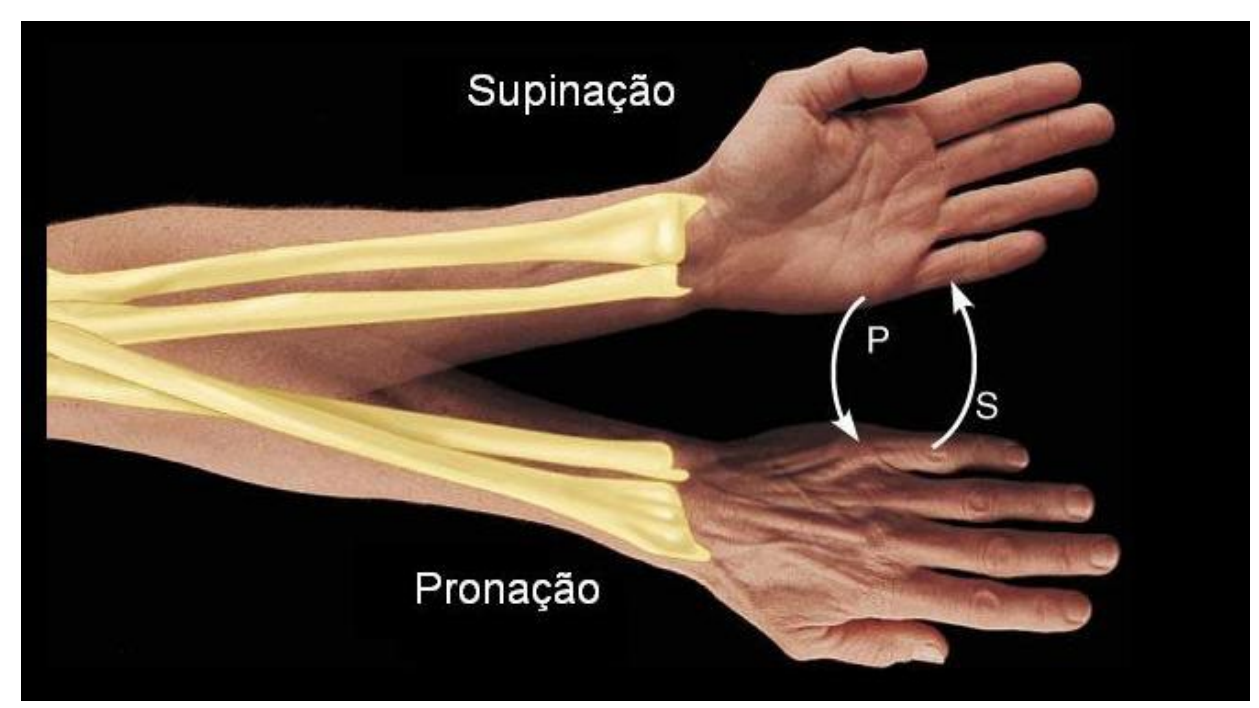

Fig. 7: Rotação: supinação e pronação. Fonte: Blog - Home work strong. ${ }^{26}$

Trata-se de um fundamento que já instigava o interesse de estudiosos como Breithaupt (1909), Matthay $(1932,1939,1947)$ e Ortmann (1929). Entretanto, sua aplicação nos remete a tempos mais remotos, ou seja, existem passagens no repertório de teclado que requerem a realização obrigatória de tais gestos, mesmo que inconscientemente. As evidências tornam-se ainda mais nítidas na escrita de Chopin e Liszt e nos fazem ponderar que este tipo de movimento já integrava o ato de executar, ainda que com poucos comentários específicos. O esforço em investigá-la causou divergências de opiniões, mas podemos notar uma evolução no seu entendimento por meio de trabalhos como o de Taubman e Fink (1992, p.29).

Breithaupt (1909, p.31-32), representante do assim denominado culto do alto grau de relaxamento, defendia que a rotação seria realizada sem a participação ativa dos dedos e mãos. O movimento rotatório seria efetivado pelo antebraço, que oscilaria em torno de seu eixo enquanto a mão continuaria passivamente o movimento e se destinaria a passagens de trêmolos, saltos e oitavas quebradas. Ortmann (1929, p.76-77) e Fraser (2011, p.203) defendem tanto a existência da rotação de antebraço quanto de todo o

26 Disponivel em: http://homeworkstrong.blogspot.com/2013_04_01_archive.html. 
braço. Matthay (1947, p.53), assim como Taubman e Timakin (1984, p.79), concorda que o movimento deve ser realizado a partir da junção antebraço e braço, ou seja, no cotovelo, mas defende a importância da integração dos dedos e da mão na rotação. Matthay (1947, p.30) ponderava que a rotação deveria ser usada em todas as notas, e Ortmann (1929, p. 194) admitia que, de alguma maneira, modificada ou não, ela está sempre presente na técnica avançada. Já Schultz (1936, p.192) considerava que a rotação fornece pouca efetividade em abaixar a tecla e que deve ser usada apenas em intervalos maiores que uma quarta. Para Matthay (1932, p.50), a rotação poderia ser invisível, quando usada para o ajuste de cada dedo em sua posição, ou visível, quando usada em maior amplitude, como nos trêmolos. A direção da rotação é dada a partir do último dedo usado em direção ao próximo. Cada dedo age, então, como pivô para o seguinte e, quanto maior a velocidade, menor será o movimento rotatório.

De acordo com Milanovic (2011c, p.116), para Taubman, a rotação, juntamente com o movimento de in and out, que consiste no pequeno deslocamento da mão para dentro ou para fora do teclado, de acordo com a necessidade de se aproximar ou afastar das teclas brancas ou pretas, são importantes porque ajudam a compensar a diferença de tamanho e força entre os dedos. Para tal propósito, a autora aconselha o posicionamento do braço como suporte de cada dedo na rotação, fornecendo apoio e equalizando a potência dos mesmos, permitindo o funcionamento do aparato como uma unidade e evitando, assim, o isolamento dos dedos. Cada dedo contará, portanto, com o apoio de um poderoso sistema. Dessa maneira, a abordagem proposta por Taubman refuta a necessidade de fortalecimento de dedos mais fracos, como o caso do quarto dedo, pois, apoiados pelo antebraço, cada um dos cinco dedos está respaldado e em condição de igualdade. Os pequenos ajustes para o interior do teclado (in), por sua vez, permitem que dedos de menor extensão, como o polegar, alcancem a área das teclas pretas do teclado ou que dedos de maior extensão se afastem dessa área (out), de acordo com as exigências da configuração motívica ou pela necessidade de localizar-se nas teclas brancas.

Dorothy Taubman, portanto, concorda com Matthay (1947, p.59) quanto à afirmação de que a rotação ajuda a posicionar o braço atrás de cada dedo para, coordenadamente, auxiliá-los em seu trabalho. Entretanto, Taubman parece dar um passo além de Matthay. No artigo "The Taubman Approach to Piano Technique: What it is and What it isn't", Milanovic (2011b, p.5) afirma que a pedagoga americana acreditava que o autor inglês não havia explicado com clareza os diferentes tipos de rotação, referindo-se especialmente à rotação dupla. Matthay (1947, p.50) acreditava na existência de duas formas indispensáveis: os movimentos rotatórios, presentes em trêmolos, e as ações rotatórias invisíveis, presentes entre cada nota. Taubman, por sua vez, estabelece duas classificações: as rotações simples e as duplas. Em sua concepção, a rotação simples constitui aquela em que há mudança na direção do movimento, ou seja, quando tocamos em direções opostas. Em um trêmolo, trinado ou oitavas quebradas, por exemplo, quando a primeira nota retorna para a segunda, há uma modificação em sua direção, e o movimento apresenta uma continuidade. Em outras palavras, o movimento preparatório constitui o resultado da continuação do movimento executado pela nota anterior. Para 
a autora, somente no momento em que a última nota for tocada, deve-se posicionar a unidade dedos-mão-antebraço verticalmente em relação ao teclado. A quantidade de inclinação dependerá da distância da próxima nota. Dessa maneira, intervalos de maior extensão exigem movimentos rotatórios maiores. Taubman defende que o antebraço (não o punho) deve iniciar a rotação e que os movimentos, maiores no começo, devem ser gradualmente minimizados.

Já em uma escala ascendente de dó maior, por exemplo, as notas Ré e Mi se direcionam para a direita, ou seja, não há mudança na direção. Nesse caso, seria usada uma rotação dupla. Sua duplicidade é justificada pela exigência de duas ações: o movimento preparatório, que faz com que a unidade seja elevada na direção do dedo que havia tocado previamente, e o toque para baixo, executado nessa mesma direção. Assim, na rotação dupla, cada dedo finaliza o movimento, diferentemente do que ocorre na rotação simples, em que a oscilação é constante. Todavia, faz-se necessário lembrar que a rotação dupla deve proporcionar uma fluidez de movimento, ou seja, torna-se importante evitar a execução de qualquer pausa na ação, tanto na rotação propriamente dita quanto no movimento preparatório. A rotação dupla facilita os dois movimentos básicos que realizamos ao tocar piano: o levantamento e a queda dos dedos, além de permitir o movimento lateral rápido ao longo do teclado. Quando minimizada, torna-se invisível. Pode ser encontrada também em passagens de oitavas, intervalos e acordes. O entendimento do funcionamento dos movimentos de rotação contribui de maneira crucial para o afastamento de tensão e para a obtenção da sonoridade desejada.

A Fig. 8 representa um exemplo de rotação simples, já que notamos uma mudança no sentido das semicolcheias da mão direita. A passagem demonstrada na Fig. 9, por sua vez, mostra um exemplo de combinação de rotações simples e duplas. A semínima em anacruse para o primeiro compasso do improviso op. 90 n. 2 de Schubert (Sib), juntamente com as duas primeiras colcheias do primeiro grupo de tercinas do primeiro compasso (Sol-Sib), constituem rotações simples. Já a última tercina do primeiro grupo e as duas tercinas do segundo grupo, por exemplo, representam rotações duplas (Lab-Sol-Fá), pois não há mudança na direção da passagem (descendente). A passagem do Fá para Mib, entretanto, configura uma rotação simples. Devemos lembrar que, para Taubman, toda passagem de polegar constitui uma rotação simples, a menos que seja seguida novamente pelo polegar. Segundo Milanovic (2011c, p.112), o polegar sempre toca em sua própria direção. Dessa maneira, o polegar da mão esquerda gira para a direita e o polegar direito gira para a esquerda. Em uma passagem de polegar descendente de mão direita, como é o caso do exemplo da Fig. 9 (Fá-Mib do compasso 1), o polegar gira para a esquerda, mesma direção do movimento preparatório e em direção oposta à rotação. 


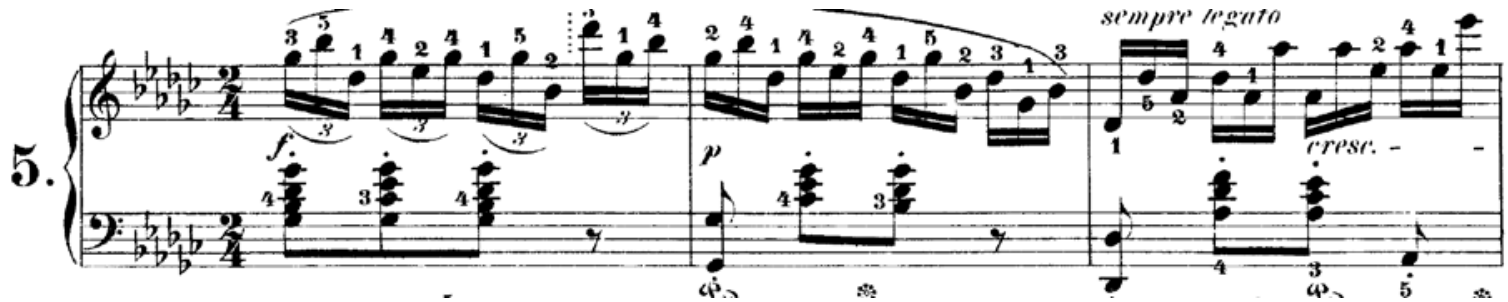

Fig. 8: F. Chopin etude op. 10 n. 5 c. 1-3: rotação simples

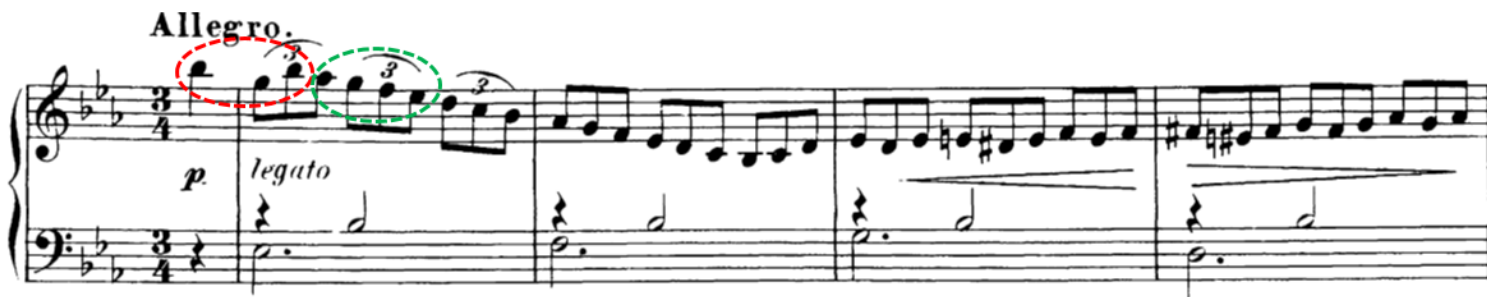

Fig.9: F. Schubert Improviso op. 90 n. 2 c. 1-4: rotações simples e duplas

Como solução técnica para a realização das oitavas, Matthay (1932) defendia o uso da rotação, que se tornaria invisível. Segundo o autor,

A execução de oitavas geralmente falha simplesmente devido ao enrijecimento rotacional. Em todas as passagens de oitavas e de notas duplas, os leves, mas invisíveis esforços rotatórios na direção do polegar, devem ser repetidos livremente a cada vez, individualmente, para cada oitava, e da mesma maneira para qualquer outra passagem em notas duplas, sextas etc. (MATTHAY, 1932, p.23, tradução nossa). ${ }^{27}$

Em consonância com Matthay, Dorothy Taubman sugeria também o uso da rotação nas oitavas, mas especificava a sua natureza. Segundo a pedagoga americana, somente a primeira oitava seria realizada com rotação simples. As demais se configurariam como rotação dupla e, assim como Matthay $(1947$, p.63) sugeria, sempre partiriam em direção ao polegar. Esse tipo de rotação é importante porque permite que o peso do braço seja equalizado atrás de cada dedo, proporcionando uma maior soltura e qualidade de movimento. Além disso, permite a não fixação da mão, que só deve abrir prestes a efetuar o contato com o teclado. A parte superior do braço funciona como eixo, e o antebraço dispõe de todo o poder para realizar os mais diferentes ataques, transmitindo o

27 Original: "Octave playing usually fails simply owing to rotational stiffening. In all octave and double-notes passages the required slight (but invisible) rotatory exertions towards the thumb must be repeated freely each time, individually, for each octave, and likewise for any other passage in double-notes, sixths etc." (MATTHAY, 1932, p.23). 
peso necessário para abaixar a tecla. Combinado com a mão, o antebraço inicia a ação, e o punho simplesmente sente essa flexibilidade em recuperar as respostas do ataque de uma oitava para outra, especialmente em oitavas rápidas. A ação dos dedos seria garantida pelo contato com o teclado. Taubman recomenda o não estacionamento da mão nas oitavas, mas sim uma ação contínua, como o repique de uma bola, que realiza movimentos ascendentes e descendentes.

Para Taubman, a rotação deve estar presente também nos acordes, sempre em direção ao polegar. Essa ação permite o suporte do braço aos dedos, que sentirão o rebote de subida da tecla na mesma proporção com que ela foi abaixada. O rebote, assim como nas oitavas, permite que o movimento entre os acordes seja contínuo e evita a tensão ocasionada pela fixação das posições. Para a pedagoga, o mecanismo da gravidade será responsável pela abertura da mão entre um acorde e outro ou entre oitavas. Para Thomas Mark (2003), a amplitude de abertura da mão está condicionada à liberdade de ação da articulação carpometacarpal, que conecta os dedos ao punho, não ao movimento de estiramento dos dedos. Assim como Taubman, considera ineficiente a imobilização da mão em posições predeterminadas. Segundo o autor,

Ajustar a mão com antecedência, ou mantê-la fixa na posição, simplesmente cria tensão. Você pode permitir que sua mão caia no acorde ou na oitava sem ajustá-la com antecedência, e você tocará com menos tensão. Confie, você não vai sentir falta disso (ou você vai aprender). A execução de acordes e oitavas parecerá sem esforço em comparação com o que se sente com a mão fixada na posição. Uma imagem que ajuda muitos pianistas a abrirem a mão na quantidade certa é "deixe o piano abrir a sua mão". Certifique-se de pensar na abertura de sua mão não como uma extensão dos dedos, mas como a abertura das articulações carpo metacarpal, como um guarda-chuva. (MARK, 2003, p.94, tradução nossa). ${ }^{28}$

Os movimentos rotatórios promovem a liberação do antebraço, permitindo ações ergonomicamente eficientes e na medida para alcançar o efeito desejado, ou seja, o comando do bem-estar físico ao tocar.

\section{d) Movimentos semicirculares inferiores e superiores}

Os movimentos semicirculares inferiores e superiores, em constante demanda nas obras de Chopin, Liszt e Thalberg, receberam atenção especial de Deppe (1885, p.325), que acreditava que esse gesto contínuo unificava e conciliava as atividades de uma mão leve com o movimento lateral do punho flexível e com a queda livre, base de seus ensinamentos. Taubman utiliza o termo shaping, configuração ou contorno, para descrever o ato de realizar um movimento baseado no contorno da linha ou grupo de notas que serão reproduzidas. Entretanto, segundo Milanovic (2011c, p.121), na aborda-

28 Original: "Setting the hand in advance, or holding it fixed in position, simply creates tension. You can allow your hand to fall on the chord or octave without setting it in advance, and you'll play with less tension. Trust it, you won't miss (or you'll learn not to). Chords and octaves will feel effortless in comparison to how they feel with the hand fixed in position. An image that helps many pianists open the hand by just the right amount is 'let the piano open your hand'. Be sure to think of the opening of your hand not as a spreading of the fingers but as an opening from the CMC joints, like an umbrella" (MARK, 2003, p. 94). 
gem Taubman o gesto não é iniciado pelo punho. $O$ shaping constitui um movimento lateral e elíptico do antebraço com o punho e a parte superior do braço movendo-se passivamente em resposta a esse estímulo. Existem dois tipos básicos de shaping: o undershape, como o nome já indica, é caracterizado por um movimento de semicírculo para baixo, e no overshape o movimento é para cima. Estas ações dependem dos dedilhados escolhidos, das mudanças de direção e do ajustamento entre as teclas brancas e pretas anteriormente descrito nos ajustes in and out. Apenas um tipo de shaping será adequado para determinado grupo de notas. Dessa forma, a fluência e a naturalidade do gesto serão sentidas intuitivamente se o tipo de shaping estiver correto. O propósito do shaping é tanto técnico quanto interpretativo. Além de proporcionar maior facilidade e organicidade na execução, contribui para a criação de novas cores sonoras, propicia continuidade nas frases longas e clareza rítmica nos padrões escolhidos.

No primeiro compasso da Fig. 10, podemos detectar amplos movimentos de undershaping combinados com pequenos movimentos de overshaping. Já no segundo compasso, observamos amplos movimentos de overshaping aliados aos pequenos movimentos de undershaping:

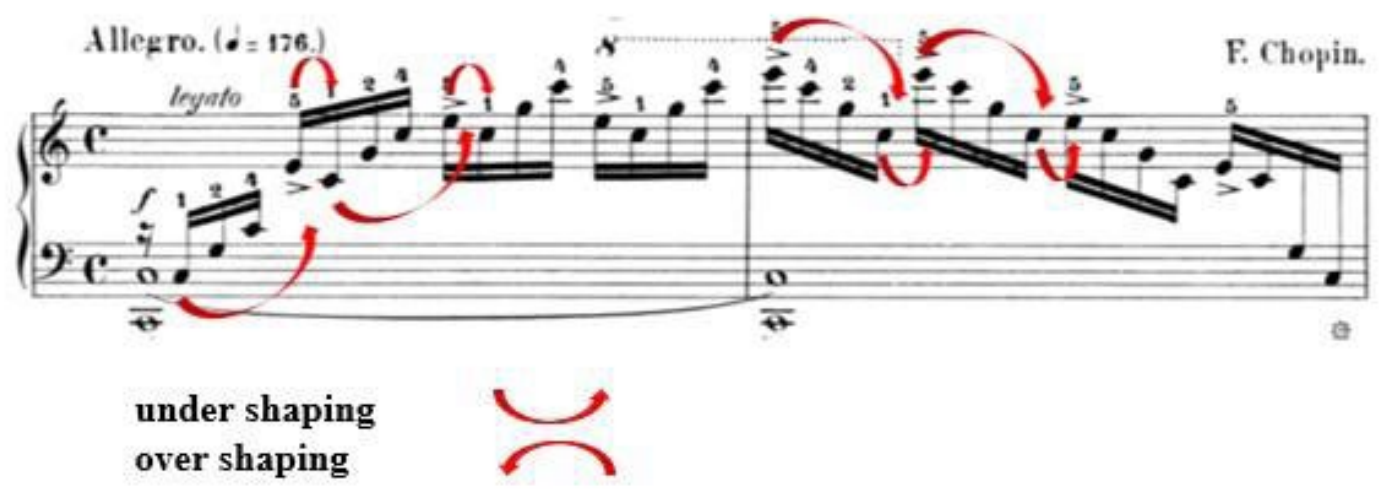

Fig. 10: F. Chopin Etude op. 10 n. 1 c. 1-2: under/over shaping

\subsubsection{Deslocamento lateral progressivo no teclado}

O deslocamento lateral progressivo no teclado constitui um dos aspectos mais importantes da técnica pianística. Essa movimentação do braço no piano é indispensável para a execução dos padrões básicos, como escalas, arpejos e saltos, pois auxilia a passagem do polegar e contribui para a fluência da execução. Ortmann (1929, p.204), por meio de seus experimentos, explicou que as unidades requisitadas para a execução do deslocamento lateral mudam de acordo com a distância a ser percorrida. No meio do teclado, o movimento é feito pelo antebraço agindo a partir do cotovelo. Já nos extremos dos registros grave e do agudo, pode envolver até mesmo a rotação do ombro.

Em se tratando da execução de escalas e arpejos, a consciência da função do polegar e do deslocamento lateral é muito importante. O contraste entre a execução de escalas em diferentes andamentos reside no fato de que, em uma escala lenta, notamos o movimento do polegar por baixo da mão, já na escala tocada com maior velocidade, 
não há tempo hábil para essa passagem, ocorrendo apenas uma série de mudanças de posições auxiliadas pelo deslocamento lateral do braço. Em decorrência dessa passagem, a escala lenta contempla dois movimentos de braço por oitava, enquanto na escala rápida se percebe um movimento único e sintético, semelhante a um glissando.

A incompatibilidade entre a execução de escalas nos andamentos lento e rápido foi discutida por Ortmann (1929, p.250). Para o autor, a escala tocada velozmente produz um movimento curvilíneo e contínuo devido aos movimentos para frente e para trás de todo o braço, decorrentes da mobilidade do punho, e nenhum ponto de descanso é visível. Entretanto, na escala lenta, o autor enfatiza a passagem do polegar por baixo da mão por meio de um movimento de rolamento em seu eixo longitudinal. Nessa ocasião, o terceiro dedo deve levantar para permitir que o segundo dedo auxilie no deslocamento lateral e na chegada da nova posição. Para o autor, a dificuldade maior dessa ação reside no seu movimento vertical do polegar, e não na passagem em si.

O deslocamento lateral progressivo do braço por meio da formação da imagem do glissando na execução das escalas e arpejos foi destacado por Whiteside (1955, p.106108). A autora defendia a responsabilidade do braço em ambos os movimentos e a cooperação de todas as alavancas e do fluxo rítmico como apoio e guia para esta tarefa tão frequente no estudo e na execução pianística. Para a pedagoga, o braço produz a ação contínua das escalas, enquanto os dedos promovem a conexão entre a energia do braço e a nota desejada, sem produzir pressão excessiva. Para Whiteside, o movimento lateral deve ser iniciado na parte superior do braço, enquanto, para Taubman, o antebraço é o propulsor da ação.

Taubman considera a passagem do polegar flexionado na altura da palma da mão como perigosa. Para a pedagoga, esse movimento pode resultar no uso simultâneo de dois músculos opostos, isto é, na dupla tração muscular, uma ação que impede o desenvolvimento de uma técnica saudável e virtuosa. Taubman acredita que, para se mover, o polegar deve ser auxiliado pelo uso da rotação do antebraço, movimento responsável por combinar a ação dos dedos em velocidade com o deslocamento lateral do braço, descrito pela autora por walking hand and arm. Esse ajustamento permite que amplas distâncias sejam percorridas sem que haja estiramento desnecessário dos músculos das mãos e dos braços. Sendo assim, o domínio desse procedimento torna-se essencial para a execução de outro importante elemento da técnica pianística: o arpejo.

Muitos especialistas acreditam na equivalência dos movimentos básicos das escalas e arpejos. Ortmann considerava que "arpejos são grandes escalas" em termos de movimento muscular (ORTMANN, 1929, p. 62, tradução nossa). A diferença entre dois dos mais usados elementos da escrita pianística centra-se no fato de que o arpejo acresce ao nível de desafio na execução, dada a necessidade de percorrer distâncias maiores.

O deslocamento lateral progressivo no teclado exerce um papel significativo na execução dos saltos, elemento técnico frequentemente lembrado por sua dificuldade. Muitos autores, como Neuhaus (1973, p.108) e Ortmann (1929, p.166), concordam que a trajetória de um salto não representa uma linha reta, mas, sim, uma curva. Segundo Ortmann, o deslocamento, além de curvilíneo, é assimétrico. Para maximizar a chance de acertar o alvo e propiciar que a força na tecla de destino seja aplicada quase verti- 
calmente, inicia-se o movimento na horizontal e finaliza-se em um ponto entre a linha horizontal e a vertical. Ortmann (1929, p.160) defende que, durante um salto, deve haver inicialmente uma aceleração da velocidade estacionária para a velocidade máxima da mão e do braço e uma desaceleração antes da chegada à nota desejada. Segundo sua abordagem, os movimentos curvilíneos são melhores que aqueles angulares, e o salto faz uma curva de forma elíptica, que muda também ligeiramente de acordo com a intensidade e a velocidade. Matthay (1947, p.82) recomendava que, para saltos de menos de duas oitavas, o cotovelo e a parte superior do braço ficassem estacionários, mas que, para se fazer isso, antes do salto, o cotovelo deveria estar longe o suficiente para alcançar a nota mais distante. Para saltos de mais de duas oitavas, a parte superior do braço deveria se mover. Abby Whiteside (1997, p.50-51) sugere uma abordagem bastante instigante desse elemento. Para a autora, o aprendizado da técnica deve ser iniciado justamente com saltos, e não com escalas, pois os mesmos ajudam no desenvolvimento do ritmo básico responsável pelo desejo da coordenação. Infere-se que a coordenação dos músculos maiores seja mais acessível que a dos músculos menores, como aqueles exigidos no trabalho do sistema dedos-mãos-braço das escalas. As distâncias no teclado são medidas e controladas pelas ligeiras torções na parte superior do braço, responsável por tornar as grandes ações do antebraço disponíveis. O antebraço, por sua vez, produz movimentos rápidos de extensão por meio do deslocamento lateral da mão. O controle situa-se, portanto, no centro, e, quando isso ocorre, as distâncias parecem mais curtas.

Taubman acrescenta um importante elemento a essa perspectiva da realização dos saltos: a rotação. Segundo Milanovic (2011c, p.125-126), a pedagoga americana classifica os saltos em dois tipos: staccato e legato. O primeiro corresponde ao movimento realizado entre os mesmos dedos, geralmente 1-1 ou 5-5. Nele, o movimento, que deve ser circular, adquire uma forma de u com um vetor para baixo (U囚). O segundo representa o deslocamento efetuado entre dedos diferentes. Esses saltos exigem um sentido de conexão entre os sons e seu funcionamento depende do emprego da rotação. Nesse caso, dado o movimento preparatório rotacional, Taubman confere à primeira nota, e não à nota-alvo, a maior importância. Quando há saltos nas duas mãos simultaneamente, uma mão, geralmente aquela que tem a tarefa mais fácil, deve iniciar o movimento um pouco antes da outra, para que maior atenção seja dada àquela que enfrenta a distância mais desafiadora. Em saltos de notas duplas, deve-se ter como guia a menor distância formada entre seus intervalos. Taubman aconselha uma breve respiração antes do salto, e Kochevitsky (1967, p.43) sugere um planejamento prévio imediatamente precedendo o salto associado ao controle visual.

A Fig. 11 representa um salto em staccato por realizar-se com os mesmos dedos (oitavas, ambas com dedos 1 e 5). De acordo com a sugestão de Taubman, o pianista deve orientar-se pela menor distância. Nesse caso, o intervalo espacial formado pela oitava inferior do segundo acorde (Lá natural) e a oitava superior do terceiro acorde (Sib) é menor do que a distância entre as duas oitavas superiores ou inferiores desses acordes. Deve-se, portanto, focar na relação formada entre o intervalo do dedo 1 do primeiro acorde e o dedo 5 do segundo. 


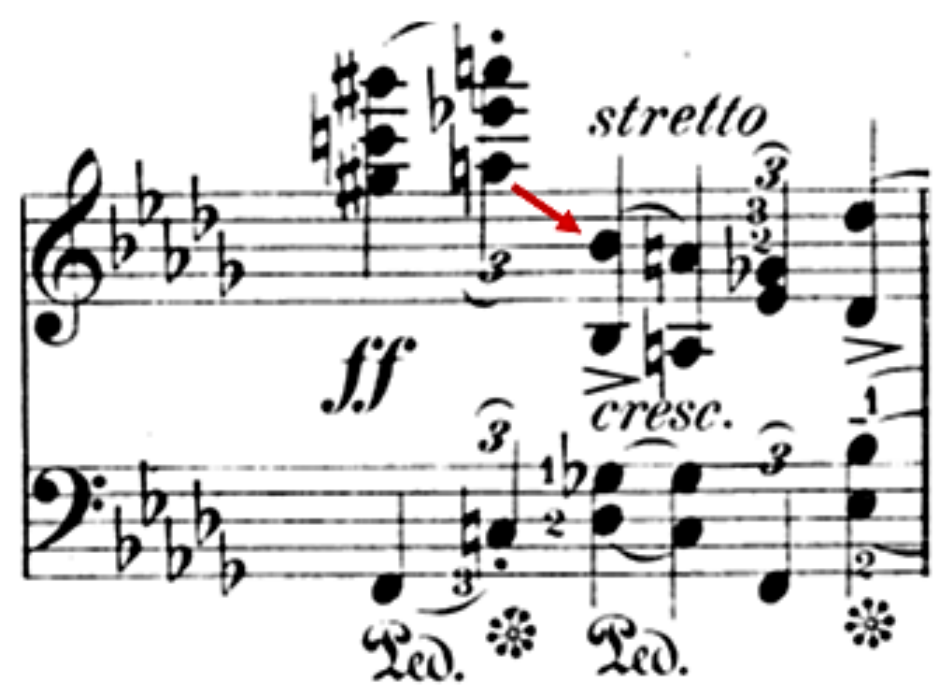

Fig. 11: F. Chopin Sonata op. 35 Mov I c. 162: salto em stacatto

No exemplo a seguir, no compasso 197, observamos um salto que demanda um sentido de conexão, por ser realizado com o uso de dedos distintos (polegar e quinto dedo). Nesse caso, recomenda-se o uso da rotação dupla com um movimento preparatório amplo aliado ao deslocamento lateral do antebraço.

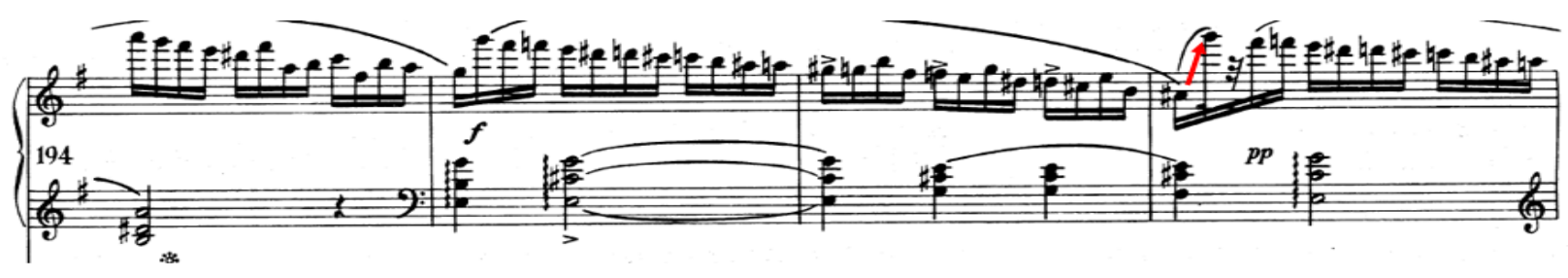

Fig. 12: F. Chopin Concerto n. 1, Movimento I, c. 194-197: salto em legato

\subsubsection{Agrupamentos de leitura e realização}

O agrupamento ocupou um lugar importante nos trabalhos de Busoni e Taubman e sua compreensão é uma das chaves para o desenvolvimento técnico. De acordo com Kogan (1971, p.55-59), Busoni propunha que as passagens musicais registradas na partitura e baseadas em regras de agrupamento métrico frequentemente causam, de fato, distorções melódicas e entraves técnicos. Ele cria, então, o termo "fraseado técnico", que corresponde ao que conhecemos como agrupamento. Consiste na subdivisão da passagem em unidades menores que tenham similaridades entre si para facilitar a automação dos movimentos. Essa distribuição depende da posição das notas e da com- 
binação entre teclas brancas e pretas, dos motivos musicais e da mudança de direção. Em outras palavras, o agrupamento a ser formado depende do entendimento do seu desenho melódico em relação à configuração no teclado. Segundo Kogan (1971, p.56), o fraseado técnico deve ser mental, ou seja, ouvido apenas pelo intérprete, que deve prestar atenção tanto na estrutura métrica quanto motívica da passagem. Por isso, é importante que seja aplicado cuidadosamente para que o fraseado musical seja realçado.

Savshinsky (1961, p.222-247), ao reconhecer a importância do trabalho de Busoni, diz que no agrupamento alguns fatores devem ser levados em conta: a simplicidade e uniformidade da direção e dos intervalos, a unificação das oitavas tocadas nas teclas pretas ou brancas e o uso da nota central como ponto de apoio. Também aponta que nesse fraseado técnico a dificuldade não está nas limitações das posições em si, mas na capacidade de conectá-las e na manutenção do caráter musical.

Segundo Milanovic (2011c, p.122), para Taubman o agrupamento é uma ferramenta tanto técnica quanto interpretativa e, além de auxiliar na execução das passagens, tem um papel importante na sua memorização, pois constitui uma forma lógica de organizar a passagem. O agrupamento pode ser feito de acordo com o estabelecimento de várias relações, tais como: a disposição intervalar, o sentido da passagem ou o direcionamento da nota mais curta para a mais longa. Sabemos que a constante mudança de direcionamento pode causar fadiga e perda de velocidade. O agrupamento faz com que se pense cada vez em um novo começo. Há, portanto, a reorganização do pensamento e a solução da confusão inicial. Além disso, o agrupamento pode contribuir para evitar o estiramento desnecessário das mãos nos intervalos amplos.

Seguem alguns exemplos de agrupamento.

- Por relação intervalar ou cordal:

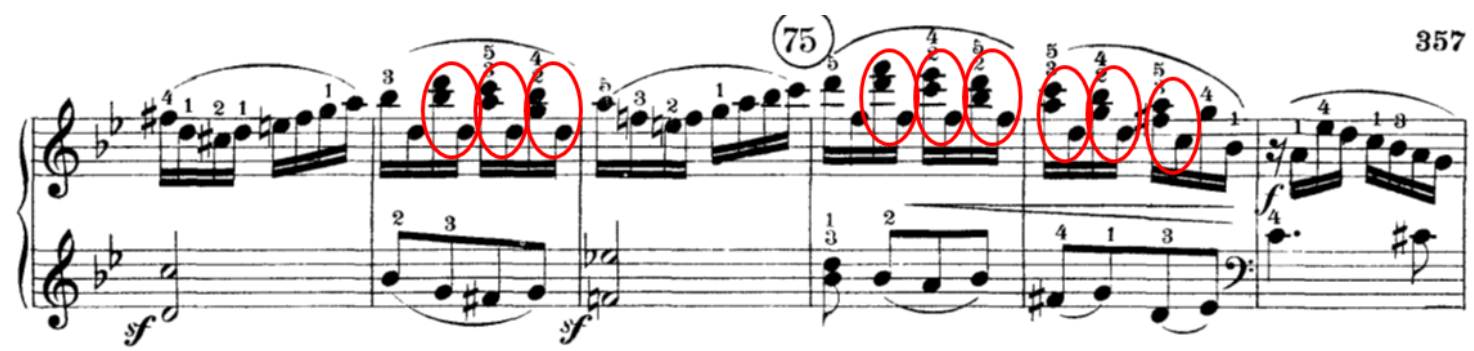

Fig. 13: L.V. Beethoven, Sonata op. 49 n. 1, Mov. I, c. 72-77: agrupamento por relação intervalar 
- Pela direção (sentido):

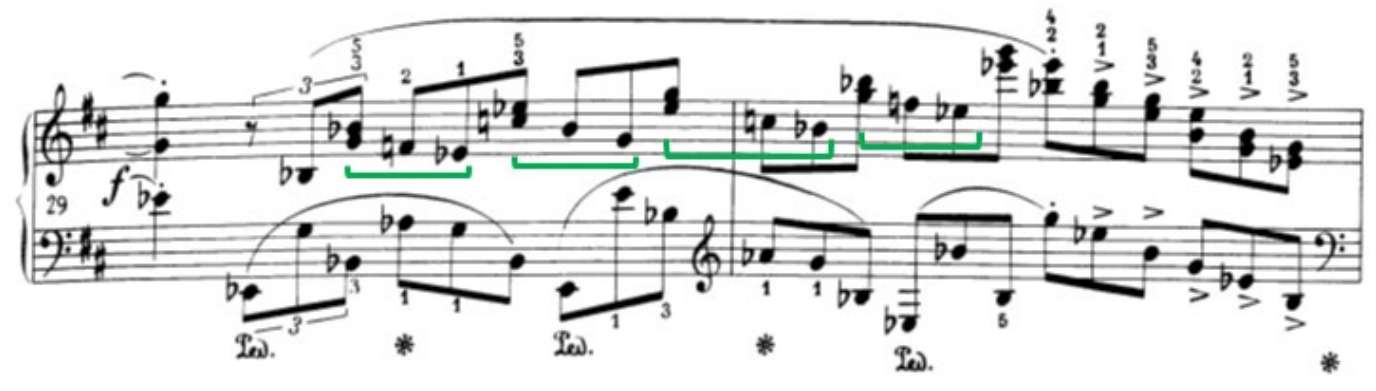

Fig. 14: F. Chopin, Sonata op. 58, Mov. I, c. 29-30: agrupamento pela direção (sentido)

- Pelo direcionamento da nota curta para a longa:

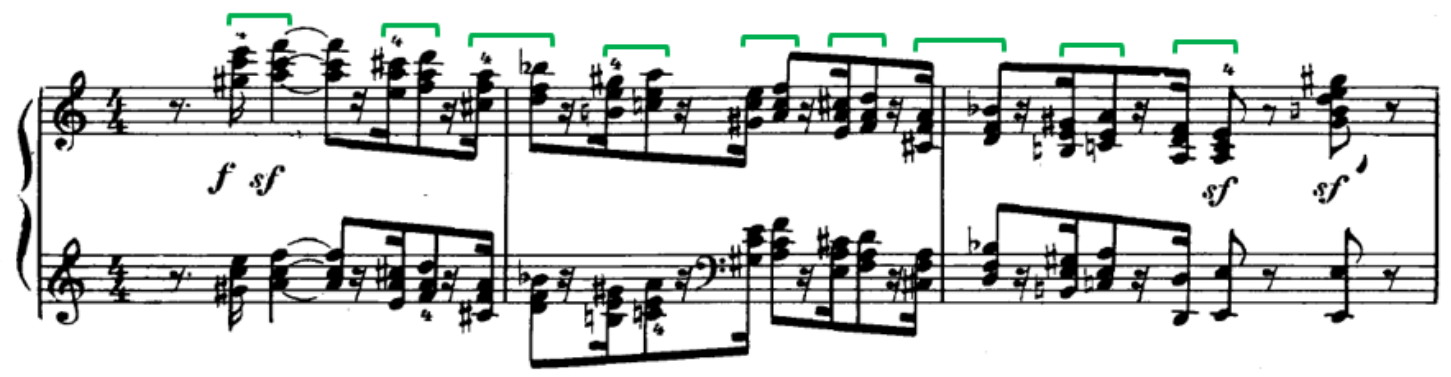

Fig. 15: R. Schumann, Piano Concerto, Mov. I, c. 1-3: agrupamento pelo direcionamento da nota curta para a longa

\section{CONSIDERAÇÕES FINAIS}

Em suma, apesar de algumas divergências terem sido descritas, notamos que há um consenso na procura por uma maneira inteligente e eficaz de tocar piano. A consciência da velocidade de descida da tecla e da sua relação com a dinâmica, andamento e tipos de toque, bem como a internalização do equilíbrio entre contração e relaxamento, parecem integrar o estudo e a busca por uma técnica avançada e controlada. $O$ trabalho coordenado das várias alavancas - dedos, mãos, antebraço, braço, ombros e tronco -, seu correto alinhamento e o auxílio dos movimentos circulares, laterais e rotatórios, aliados à organização motívica e rítmica por grupos, também são considerados ferramentas importantes para alcançar o tão sonhado virtuosismo saudável. Entretanto, é fundamental saber que a técnica não constitui um fim, mas sim um meio que, mediante uma pesquisa diária e individual, ajuda a desvendar a expressão da alma do artista, sua personalidade, seu desejo musical, sua fantasia.

Nesse sentido, visando contribuir para a formação ampla do artista, a ordenação dos principais conceitos da técnica pianística em pilares permite que o pianista acesse com disponibilidade física tais princípios mecânicos e musicais e crie um repertório de 
movimentos eficientes para a resolução de suas possíveis dificuldades de execução. A adequação dos movimentos às necessidades de cada passagem auxilia no desenvolvimento da consciência corporal, essencial não só na formação técnica sólida, como também na busca da qualidade e variedade sonora. $E$, não menos importante, permite que o músico desfrute de uma longevidade proporcionada pelo uso consciente do corpo e por meio de um estudo inteligente, que prime não pela repetição randômica, mas pelo diagnóstico eficaz da dificuldade, pela reflexão cuidadosa da solução e pelo desempenho performático e sonoro idealizado e artisticamente realizado.

Por fim, os sete pilares aqui apresentados e discutidos têm por objetivo liberar o pianista de entraves e obstáculos mecânicos para que seu pensamento se volte para a qualidade do fazer musical. Tocar torna-se uma atividade prazerosa, e não uma frustração. Recomendamos fortemente que os pianistas se afastem definitivamente da imagem do artista sofredor, que passa horas em frente ao instrumento sem resultados, uma visão romântica do músico que se doa inteiramente ao instrumento, em uma espécie de autoflagelação. É ilusório separar a pessoa do artista, o indivíduo do profissional, o corpo da mente, a técnica da música. O sucesso do pianista passa, assim, pela construção de um indivíduo saudável física e psicologicamente, que seja capaz de transmitir suas ideias plenamente, sem ressalvas. Esse êxito permeia, dessa maneira, a formação de um músico que possa realmente desfrutar da dádiva de seu ofício, afinal não são todos que têm o privilégio de trabalhar e conviver diariamente com o que a humanidade produziu de mais esplêndido e grandioso, a virtuosidade da arte musical.

\section{REFERÊNCIAS}

BERNSTEIN, Seymour. With your two hands. New York: Schirmer Books, 1981.

BIENFAIT, Marcel. As bases da fisiologia da terapia manual. Trad.Angela Santos. 2. ed. São Paulo: Summus, 2000.

BONPENSIERE, Luigi. New Pathways to Piano Technique. New York: Philosophical Library, 1953.

BREITHAUPT, Rudolf Maria. Natural Piano-Technique: School of Weight-Touch. 2. ed. Trad. John Bernhoff. Leipzig: C.F. Kahnt Nachfolger, 1909.

CHIANTORE, Luca. Historia de la técnica pianística. Madrid: Alianza, 2001.

DEPPE, Ludwig. Armleiden der Klavierspielen. Deutsche Musikerzeitung, p. 325, 1885.

FIELDEN, Thomas. The science of pianoforte technique. London: Macmillan and Co, 1949. 
FINGER Use: Curling versus Curving - an excerpt from the Taubman 10 DVD Series. [S. l.: s. n.], 2008. 1 vídeo (1 min). Publicado pelo canal The Golandsky Institute. Disponível em: https://youtu.be/_ydx84Sp1rc. Acesso em: 17 jan. 2018.

FINK, Seymour. Mastering Piano Technique: A Guide for Students, Teachers, and Performers. Portland: Amadeus Press, 1992.

FRASER, Alan. The Craft of Piano Playing: A New Approach to Piano Technique. 2. ed. Lanham, Maryland: The Scarecrow Press, 2011.

GAT, Jozsef. The technique of piano playing. London: Collet's, 1980.

GERIG, Reginald. Famous Pianists and Their Technique. 2. ed. Bloomington: Indiana University Press, 2007.

KOCHEVITSKY, George. The Art of Piano Playing: A scientific approach. Miami: Summy-Bichard Company, 1967.

KOGAN, Grigory. Feruccio Busoni. Moscow: Compositores Soviéticos, 1971.

LISTER-SINK, Barbara. Let's Get Physical: Técnica - uma conversa com Barbara ListerSink. [Entrevista cedida a] Scott McBride Smith. Keyboard Companion, v. 11, n. 1, Spring 2000.

LISTER-SINK, Barbara. Freeing the caged bird. Developing well-coordinated injurypreventive piano technique with Barbara Lister-Sink. Wingsound International, 2005. 1 DVD. Disponível em: www.freeingthecagedbird.com.

MARK, Thomas. What Every Pianist Needs to Know About the Body. Chicago: GIA Publications, 2003.

MATTHAY, Tobias. The act of touch in all its diversity: an analysis and synthesis of pianoforte tone-production. London: Longmans, Green and Co, 1903.

MATTHAY, Tobias. The Visible and Invisible in Pianoforte Technique. New York: Oxford University Press, 1932.

MATTHAY, Tobias. Piano fallacies of to-day. London: Oxford University Press, 1939.

MATTHAY, Tobias. The Visible and Invisible in Pianoforte Technique. 2. ed. New York: Oxford University Press, 1947. 
MILANOVIC, Therese Elaine. Healthy virtuosity with the Taubman approach. APPCA Conference papper. Wagga Wagga: Charles Sturt University, 2011 a.

MILANOVIC, Therese Elaine. The Taubman Approach to Piano Technique: What it is and What it isn't. APPCA Conference paper. Wagga Wagga: Charles Sturt University, 2011b.

MILANOVIC, Therese Elaine. Learning and Teaching Healthy Piano Technique:

Training as an Instructor in the Taubman Approach. Tese de doutorado. Queensland Conservatorium Arts, Education and Law. Brisbane: Griffith University, 2011c.

NEUHAUS, Henrich. The art of piano playing. Trad. K. A. Leibovich. Longwood Academic: Michigan University, 1973.

ORTMANN, Otto. The physiological mechanisms of piano technique. New York: Da Capo Press, 1929.

OSADA, Mayumi. The Lister-Sink method: A holistic approach to injury preventive piano technique. Thesis (PhD) - University of North Carolina, Greensboro, 2009.

SANDOR, Gyorgy. On piano playing: Motion, sound and expression. New York: Schirmer, 1981.

SAVSHINSKY, Samariy Ilich. O pianista e seu trabalho. Leningrado: Compositores Soviéticos, 1961.

SCHULTZ, Arnold. The riddle of the pianist's finger and its relationship to a touchscheme. Chicago: The University of Chicago Press, 1936.

TAUBMAN INSTITUTE. Choreography of the hands: The work of Dorothy Taubman. Amherst, MA: Sawmill River Productions, 1986. 1 vídeo, extensão mp4.

TAUBMAN INSTITUTE. The Taubman Techniques: An in-depth analysis of a technique for virtuosity and prevention of injuries among musicians. Medusa, NY: Taubman Institute, 1995. Vols. 1-5. 1 vídeo, extensão mp4.

TAUBMAN INSTITUTE. Virtuosity in a box: The Taubman techniques. Medusa, NY: Taubman Institute, 2003. Vols. 6-10. 1 vídeo, extensão mp4.

TIMAKIN, Evgeny Mikhailovich. Educação do pianista. Moscow: Compositores Soviéticos, 1984. 
TORRES DEL RINCÓN, Marta. La escuela anatómico-fisiológica de técnica pianística en Inglaterra y Alemania entre 1900 y 1939. Tesis (Doctorado) - Universidad Autónoma de Madrid, 2017.

WHITESIDE, Abby. Indispensables of piano playing. New York: Charles Scribner's Sons, 1955.

WHITESIDE, Abby. On Piano Playing. Indispensables of Piano Playing, and Mastering the Chopin Etudes and Other Essays, ed, Joseph Prostakoff and Sophia Rosoff. Portland: Amadeus Press, 1997. 